\title{
Turning Astrocytes from the Rostral Migratory Stream into Neurons: A Role for the Olfactory Sensory Organ
}

\author{
Mariana Alonso, ${ }^{1}$ Inmaculada Ortega-Pérez, ${ }^{1}$ Matthew S. Grubb, ${ }^{1}$ Jean-Pierre Bourgeois, ${ }^{1}$ Pierre Charneau, ${ }^{2}$ and \\ Pierre-Marie Lledo ${ }^{1}$ \\ ${ }^{1}$ Laboratory for Perception and Memory, Centre National de la Recherche Scientifique, Unité de Recherche Associée 2182, and ${ }^{2}$ Laboratory of Molecular \\ Virology and Vectorology, Institut Pasteur, 75724 Paris Cedex 15, France
}

\begin{abstract}
Neurogenesis persists within a few restricted areas of the adult mammalian brain, giving rise to neurons that functionally integrate into preexisting circuits. One of these areas, the subventricular zone (SVZ), was believed, until recently, to be the unique source providing the adult olfactory bulb $(\mathrm{OB})$ with newborn neurons. Because of the fact that neuroblasts derived in the SVZ migrate through the rostral migratory stream (RMS) en route to the $\mathrm{OB}$, the existence of candidate neural stem cells within the RMS was long overlooked. Here, we confirm and considerably extend recent evidence for the existence of adult neural stem cells within the RMS, and go on to investigate their proliferative regulation. Specifically targeting RMS-astrocytes with lentiviral vectors encoding GFP, we demonstrate that glial cells in the RMS differentiate into both $\mathrm{OB}$ granule and periglomerular interneurons. In addition, ultrastructural analysis unambiguously reveals the astrocytic nature of stem cells in the adult RMS, and patch-clamp recordings demonstrate the functional integration of RMS-derived interneurons into $\mathrm{OB}$ circuitry. Proliferative regulation was investigated via two contrasting manipulations: exposure to an odorenriched environment that enhances candidate stem cell proliferation in both the RMS and SVZ, and chemical lesion of the main olfactory epithelium that increases cell proliferation in the RMS only. New neurons in the adult $\mathrm{OB}$ can therefore arise from different neurogenic areas that can be separately regulated.
\end{abstract}

Key words: adult neurogenesis; astrocytes; interneurons; GABA; neural stem cells; stem cells

\section{Introduction}

New neurons continue to be integrated into the olfactory bulb (OB) circuit of adult mammals, including humans (for review, see Lledo et al., 2006; Curtis et al., 2007). Previous investigations have shown that astrocytes function as progenitors of the newborn neurons generated in the adult subventricular zone (SVZ) (Alvarez-Buylla et al., 2001). From there, neuroblasts migrate along a well defined pathway, the rostral migratory stream (RMS), en route to the $\mathrm{OB}$ where they differentiate into local interneurons (Luskin, 1993; Lois and Alvarez-Buylla, 1994). Unlike other neuronal precursor populations generated during development, neuroblasts in the RMS are still mitotically active,

\footnotetext{
Received Aug. 5, 2008; revised Sept. 8, 2008; accepted Sept. 11, 2008.

This work was supported by the Fédération pour la Recherche sur le Cerveau, the Agence Nationale de la Recherche (ANR-05-Neur-028-01), the Groupe Arpège, Ecole des Neurosciences de Paris, and the Fondation Institut de France. Our laboratory is a member of the Network of European Neuroscience Institutes (Grant LSHM-CT-2005019063). M.A. was supported by a grant from the Région lle-de-France (Neuropôle 07-006); I.0.-P. by a grant from the Région Aquitaine; and M.S.G. by a Marie-Curie IntraEuropean Fellowship. We thank A. de Chevigny for his help in preliminary experiments, I. Caille for advice on the mini-osmotic pump implantation technique, the PFID for technical assistance with confocal microscopy, A.-M. Le Sourd for helping us with electron microscopy experiments, $G$. Gheusi for helping us with olfactory enrichment experiments, P. Souque for his help with Mokola vector stability experiments, and S. Mejia Gervacio for helpful comments.

Correspondence should be addressed to Pierre-Marie Lledo at the above address. E-mail: pmlledo@pasteur.fr.

M. S. Grubb's present address: MRC Centre for Developmental Neurobiology, King's College London, New Hunt's House, 4th Floor, Guy's Hospital Campus, London SE1 1UL, UK.

I. Ortega-Perez's present address: INSERM Unit 679, Experimental Neurology and Therapeutics, Pitié-Salpêtrière Hospital, 47 Bd de l'Hôpital, 75651 Paris Cedex 13, France.

DOI:10.1523/JNEUROSCI.3713-08.2008

Copyright $\odot 2008$ Society for Neuroscience $\quad 0270-6474 / 08 / 2811089-14 \$ 15.00 / 0$
}

whereas astrocytes delineating the glial tubes of the RMS remain quiescent (Menezes et al., 1995; Rousselot et al., 1995; Brüstle et al., 1998; but see Peretto et al., 2005; Merkle et al., 2007).

Radial glial cells serve as progenitors for many neurons and glial cells soon after birth and they also give rise to adult neural stem cells (Merkle et al., 2004). During postnatal developmental modification of the SVZ, in its rostral extension, radial glia differentiate into astrocytes packed to form the glial tubes in the mature RMS (for review, see Bonfanti and Peretto, 2007). After the postnatal collapse of the olfactory ventricle, only the middle/ posterior part of the SVZ remains in contact with the lateral ventricles, with the anterior part forming the mature RMS. However, apart from the absence of the ependymal cellular monolayer in the RMS, the cytoarchitecture of the SVZ and RMS remains substantially similar. In this context, it is tempting to propose that astrocytes derived from radial glia, and possessing stem cell properties, might be also present throughout the entire RMS up to the core of the OB. This hypothesis is supported by data showing that after anti-mitotic treatment, fast-proliferating cells can be detected in the RMS (Gritti et al., 2002). Similarly, the transient recovery of OB neuronal populations after SVZ irradiation (Panagiotakos et al., 2007), also confirms the presence of neural precursors downstream from the SVZ. The nature and origin of these progenitors remained unknown until a recent study described GFAP-expressing astrocytes located in the most rostral part of the SVZ (Merkle et al., 2007).

The present work explores the ability of RMS-astrocytes to 
produce functionally integrated neurons in the mature $\mathrm{OB}$ circuit, and investigates whether this neural production could be regulated by the olfactory system. We used confocal and electron microscopy to reveal the glial nature of candidate RMS stem cells, whereas lentiviral labeling combined with electrophysiological recordings deciphered the identity and the functional properties of their neuronal progeny in the OB. Finally, lesion of the main olfactory epithelium (MOE) and exposure to an odor-enriched environment showed that stem cell proliferation in this most rostral neurogenic region can be regulated by the olfactory sensory organ, and can sometimes be regulated separately from adult neurogenesis in the SVZ.

\section{Materials and Methods \\ Subjects}

Two-month-old C57BL/6 mice were used throughout this study (Janvier). Mice were kept in a temperature- $\left(20 \pm 1^{\circ} \mathrm{C}\right)$ and lightcontrolled room. Food and water were available ad libitum. All experimental procedures were performed in accordance with the Society for Neuroscience and European Union guidelines, and were approved by our institutional animal care and utilization committees.

\section{Ara-C and lentiviral vector injections}

Ara-C infusions. Cystosine- $\beta$-D-arabinofuranoside (Ara-C, $2 \%$; Sigma) in $0.9 \%$ saline solution or vehicle alone was infused onto the surface of the brain with a mini-osmotic pump (Alzet; model 1007D) (flow rate 0.5 $\mu \mathrm{l} /$ hour, $6 \mathrm{~d}$ ). Mice were anesthetized with $250 \mu \mathrm{l}$ of a mixture of ketamine (Imalgene; $1.5 \%$ in PBS) and xylazine (Rompum; Bayer Health Care; $0.025 \%$ in PBS), and were mounted in a Kopf stereotaxic apparatus (Harvard Apparatus). Cannulas were implanted stereotaxically onto the surface of the brain at the coordinates: $0 \mathrm{~mm}$ anterior to bregma, $1.1 \mathrm{~mm}$ lateral of midline, and $-0.1 \mathrm{~mm}$ from brain surface.

Lentiviral vectors and stereotaxic injections. Immediately after the end of Ara-C infusion, pumps were removed and the mice were stereotaxically injected with lentiviral vector particles using the same anesthesia as described above. A replication-deficient lentiviral vector based on the HIV virus was used to express enhanced GFP driven by a CMV promoter. Lentiviral vector particles were produced by a triple-cotransfection procedure as described previously (Zennou et al., 2000). 293T cell Petri dishes were transfected with a $\mathrm{Ca}^{2+}$-phosphate precipitate containing 10 $\mu \mathrm{g}$ of p8.91 encapsidation plasmid, $10 \mu \mathrm{g}$ of pTRIPdeltaU3.CMV-GFP lentiviral vector (Sirven et al., 2000) and $5 \mu \mathrm{g}$ of a Mokola envelope expression vector (a gift from Noel Tordo, Pasteur Institute, Paris, France). This lentivirus (a lyssavirus) belongs to the Rhabdoviridae family and possesses the envelope G-protein of the Mokola virus (hereafter referred to as "Mokola vector"). Vector supernatants were collected $48 \mathrm{~h}$ after transfection, and concentrated by ultracentrifugation as described previously (Zennou et al., 2000). Physical concentrations of lentiviral vector particles were typically $\sim 17-36 \mathrm{ng}$ P24/ $\mu$ l. P24 antigen contents were assayed by ELISA (NEN). Average vector titers were in the range of $10^{8}$ transduction units (TU)/ml. Injections were performed at three coordinates, anterior relative to bregma, lateral to the midline and ventral with respect to the surface of the brain, respectively (in $\mathrm{mm}$ ): 0.75, 1.2, 1.7 and $1,1,1.9$, to target the SVZ; 3.3, 0.82, 2.9, to target the elbow of the RMS; and 5, 0.75, 2.1 to target the core of the OB. Viral particles (200 nl per site) were injected bilaterally using a nanoliter injector Nanoject II (Drummond Scientific Company) with a glass micropipette at a rate of $23 \mathrm{nl} / \mathrm{s}$. Animals were killed at the indicated survival times after vector injections.

\section{Histological analysis}

Immunohistochemistry. Mice were deeply anesthetized with sodium pentobarbital $(100 \mathrm{mg} / \mathrm{kg}$; Sanofi) and perfused through the heart with a saline solution $(0.9 \% \mathrm{NaCl})$ containing heparin $\left(5.10^{3} \mathrm{U} / \mathrm{ml}\right)$ at $37^{\circ} \mathrm{C}$, followed by $4 \%$ paraformaldehyde (PFA) in cold phosphate buffer (PB), $\mathrm{pH}$ 7.3. Brains were dissected out and postfixed in the same fixative overnight at $4^{\circ} \mathrm{C}$. Immunohistochemistry was performed on $40 \mu \mathrm{m}$ thick free-floating serial parasagittal sections cut with a vibrating microtome (VT1000S; Leica). For GFAP and PSA-NCAM immunostaining, antigen retrieval was performed for $20 \mathrm{~min}$ at $65^{\circ} \mathrm{C}$ in $1 \mathrm{~mm}$ EDTA. For SOX2 immunostaining, antigen retrieval was performed for $20 \mathrm{~min}$ at $100^{\circ} \mathrm{C}$ in $1 \mathrm{~mm}$ EDTA, $0.05 \%$ Tween. Brain sections were then washed in PBS and treated with $0.2 \%$ Triton X-100, $4 \%$ BSA in PBS for $2 \mathrm{~h}$ to block nonspecific protein binding sites and to permeabilize membranes. For BrdU staining, DNA was denatured with $2 \mathrm{~N} \mathrm{HCl}$ for $30 \mathrm{~min}$ at $37^{\circ} \mathrm{C}$. Incubation with primary antibodies was performed individually (see Table 1 for the list of primary antibodies) at $4^{\circ} \mathrm{C}$ for $2 \mathrm{~d}$ [except for anti-GFP and anti-SOX2, which were incubated overnight at $4^{\circ} \mathrm{C}$ and $24 \mathrm{~h}$ at room temperature (RT), respectively] and followed by a $2 \mathrm{~h}$ incubation at RT with corresponding Alexa-conjugated secondary antibodies (1:500; Invitrogen). For Mash1 immunostaining, the TSA signal amplification system (PerkinElmer) was used. Briefly, slices were pretreated with acetone at $4^{\circ} \mathrm{C}$ for $30 \mathrm{~s}$ for antigen retrieval. After rinsing in PBS, sections were incubated for $1 \mathrm{~h}$ in TNB blocking buffer (PerkinElmer), and incubated with Mash 1 primary antibody at $4^{\circ} \mathrm{C}$ for $2 \mathrm{~d}$. After PBS washing, a secondary goat anti-mouse biotinylated antibody (1:1000; Jackson) was added and kept at RT for $2 \mathrm{~h}$. Biotinylated antibody was visualized by using the TSA cyanine 3 system. Sections were mounted in a solution of 1,4-diazabicyclo[2.2.2] octano (DABCO; Sigma) and analyzed using either a confocal microscope or an Apotome microscope (Zeiss).

Single cell analysis of coexpression of different molecules. Expression of different proteins by $\mathrm{GFP}^{+}$cells was evaluated using double-labeling immunohistochemistry combined with analysis of single cells in three dimensions by scanning confocal laser microscopy (LSM 510; Zeiss). Images were taken with a pinhole of $1 \mu \mathrm{m}$ using a Plan-Neofluar $25 \times$ objective and stacks of 1- $\mu$ m-thick optical slices were collected through the $z$-axis $(20-40 \mu \mathrm{m})$ of tissue sections of the analyzed regions. Colocalization was evaluated in single optical planes taken through the entire $z$-axis of each cell. Only cells contained entirely within the three dimensions of a stack were included into the analysis. All GFP ${ }^{+}$cells present in the slices were scanned and analyzed (12-14 slices per animal). Data are expressed as the percentage of double-labeled cells present in each stud- 
ied region. Data from both hemispheres were pooled given that no differences in our results were found between hemispheres ipsilateral or contralateral to the osmotic pump.

Immunoelectronmicroscopy. Sixty micrometer coronal sections were cryoprotected at RT by immersion in PBS containing, successively, 10\% sucrose $+1 \%$ glycerol for $1 \mathrm{~h}$, then $20 \%$ sucrose $+5 \%$ glycerol for $2 \mathrm{~h}$, then $30 \%$ sucrose $+10 \%$ glycerol with gentle stirring overnight at $4^{\circ} \mathrm{C}$. Membranes were permeabilized by 3 freeze-thaw cycles over liquid nitrogen vapors. Nonspecific protein binding sites were blocked for $2 \mathrm{~h}$ with $4 \%$ BSA in PBS, at RT. Free-floating sections were incubated at $4^{\circ} \mathrm{C}$, in PBS $+4 \%$ BSA with rabbit polyclonal IgG anti-GFP (1:1000; Invitrogen), then rinsed in PBS. Sections were incubated at RT for $2 \mathrm{~h}$ with secondary donkey anti-rabbit biotinylated antibody (Jackson; 1:200), and $1 \mathrm{~h}$ with ABC complex (Elite PK-6100; Vector Laboratories). Sections were rinsed in PBS followed by TBS (Tris/HCl-buffered saline, 50 $\mathrm{mm}, \mathrm{pH}$ 7.6), equilibrated $5 \mathrm{~min}$ in $0.05 \%$ diaminobenzidine (DAB; Sigma) in TBS, and were finally reacted for 3 min with $0.01 \% \mathrm{H}_{2} \mathrm{O}_{2}$. The intensity of the reaction was intentionally maintained at a low level to preserve the ultrastructure of the electronluscent cytoplasm in the astrocytes (see Fig. $2 \mathrm{~B}-E$ ). In some cases, concentrations of $\mathrm{DAB}$ and $\mathrm{H}_{2} \mathrm{O}_{2}$, and reaction time, were increased threefold to significantly extend the electron-dense precipitate of oxidized DAB (see Fig. $2 F, G$ ). Sections were then rinsed in TBS and cacodylate buffer $(0.1 \mathrm{M}, \mathrm{pH} 7.4)$. The antibody scaffoldings were bridged with $2 \%$ glutaraldehyde (Sigma) for $30 \mathrm{~min}$, and rinsed in the same buffer. For electron microscopy, sections were fixed with $0.5 \%$ osmium tetroxide in the same buffer for $1 \mathrm{~h}$ and dehydrated in ascending concentrations of ethanol and propylene oxide. The $75 \%$ ethanol step included $1 \%$ uranyl acetate to contrast plasma membranes. Sections were embedded in Araldite (Polysciences). Ultrathin sections $(70 \mathrm{~nm})$ were counterstained with lead citrate and observed at $80 \mathrm{kV}$ with a Jeol 1010 electron microscope.

\section{Electrophysiological recording}

Mice were deeply anesthetized with isoflurane (Mundipharma) and decapitated. The OB and frontal cortices were rapidly dissected and placed in ice-cold artificial cerebrospinal fluid (ACSF), containing (in mM): 124 $\mathrm{NaCl}, 3 \mathrm{KCl}, 1.3 \mathrm{MgSO}_{4}, 26 \mathrm{NaHCO}_{3}, 1.25 \mathrm{NaHPO}_{4}, 20$ glucose, $2 \mathrm{CaCl}_{2}$; $\sim 310$ mOsm, pH 7.4 when bubbled with a mixture of $95 \% \mathrm{O}_{2}$ and $5 \%$ $\mathrm{CO}_{2}$ (all chemicals from Sigma), before being glued to a block of $4 \%$ agarose and placed, submerged in ice-cold ACSF, in the cutting chamber of a Leica vibratome (VT 1000S). Vibroslice blades (World Precision Instruments) were used to cut $300 \mu \mathrm{m}$ horizontal sections of the OB, which were then placed in bubbled ACSF in a warming bath at $35^{\circ} \mathrm{C}$ for $30 \mathrm{~min}$. After incubation, slices were kept in bubbled ACSF on ice for the remainder of the experiment (up to $6 \mathrm{~h}$ after decapitation).

For whole-cell recordings, individual slices were placed in a chamber mounted on an Olympus BX51WI upright microscope, and continuously perfused $(1.5 \mathrm{ml} / \mathrm{min})$ with $\mathrm{RT}\left(21-23^{\circ} \mathrm{C}\right)$ bubbled ACSF. Appropriate receptor antagonists (20 $\mu \mathrm{M}$ SR-95531/gabazine); $10 \mu \mathrm{M} \mathrm{2,3-}$ dioxo-6-nitro-1,2,3,4-tetrahydrobenzo(f)quinoxaline-7-sulfonamide disodium salt (NBQX); $1 \mu \mathrm{M}$ tetrodotoxin (TTX; Latoxan) were added to the perfusate using an automated switching system. Slices were visualized using a $40 \times$ water-immersion objective, a halogen light source, DIC filters, and a CCD camera (Hamamatsu; C7500). Fluorescent cells were visualized using appropriate TRITC and FITC filters.

We obtained whole-cell patch-clamp paired recordings from visually targeted RMS-generated newborn granule and periglomerular cells $\left(\mathrm{GFP}^{+}\right)$and preexisting interneurons $\left(\mathrm{GFP}^{-}\right)$. Patch pipettes, pulled from borosilicate glass (outer diameter, $1.5 \mathrm{~mm}$; inner diameter, 1.17 mm; Harvard Apparatus), using a P-87 Flaming/Brown micropipette puller (Sutter Instrument), had resistances of 6-10 M $\Omega$ and were filled with a cesium gluconate-based solution (in mM: 126 Cs-gluconate, 6 $\mathrm{CsCl}, 2 \mathrm{NaCl}, 10 \mathrm{Na}$-HEPES, 10 D-glucose, 0.2 Cs-EGTA, $0.3 \mathrm{GTP}, 2$ Mg-ATP, 0.2 cAMP, with $0.15 \%$ biocytin and $0.1-0.4 \%$ rhodamine; 280-290 mOsm, pH 7.3). All voltages reported are corrected for a liquid junction potential of $+10 \mathrm{mV}$ between our internal and external solutions. Interneurons born in the adult RMS were identified by either spatially coincident double label of GFP and rhodamine during record-
Table 2. List of different natural odors and chemical molecules used to enrich the olfactory environment

\begin{tabular}{ll}
\hline Acetophenone & Juniper berries \\
Amazonica & Lavender oil \\
Dill & Linalol \\
Balsamic vinegar & $(-)$-Limonelle \\
Basil & $(+)$-Limonelle \\
Cocoa & Lyral \\
$(+)$-Carvon & Massale \\
Cedar & Menthe piperite \\
Cheese & Mix morocco tea \\
Chives & Nutmeg \\
Cineol & Olive oil \\
Cinnamon & Onion \\
Cloves & Oregano \\
Coffee & Paprika \\
Cumin & Provence herbs \\
Curry & Rosa \\
Deodorant granules envirofresh apple, floral, lemon, and peach & Shallots \\
Garlic & Soybean sauce \\
Geraniol & Strawberry \\
Geranium & Tarragon \\
Golden wattle & Tandori \\
Hexanol & Tobacco \\
Honey and lemon cream & Vanilla \\
Isoamylacetate & Yeast extract \\
\hline
\end{tabular}

ing, or the presence of GFP in the pipette. GFP-targeted recordings that met neither of these criteria were discarded from our analyses.

Patch-clamp recordings were obtained via a Heka EPC9/2 amplifier coupled to Pulse acquisition software. Signals were Bessel filtered at 10 $\mathrm{kHz}$ (Filter 1) and $2.9 \mathrm{kHz}$ (Filter 2), digitized, and sampled at intervals of $20-450 \mu \mathrm{s}(2.2-50 \mathrm{kHz})$ according to the demands of individual protocols. Compensation for fast capacitance in cell-attached mode was $\sim 80 \%$ (12-13 pF, 3-5 $\mu \mathrm{s})$; after rupture, we also compensated for membrane capacitance $\left(C_{m}\right)$ but not series resistance $\left(R_{s}\right)$. With $C_{m}$ compensation inactivated, values of $C_{m}, R_{s}$ and membrane resistance $\left(R_{m}\right)$ were estimated using area, peak, and steady-state currents, respectively, observed in response to a $10 \mathrm{mV}$ membrane step. Any experiments in which $\mathrm{R}_{\mathrm{s}}$ changed by $>20 \%$ were discarded from our analyses. Peak sodium currents were measured after subtraction of scaled passive current responses to the appropriate voltage steps. Spontaneous postsynaptic currents were analyzed with Elphy software (Gerard Sadoc) using custom routines written by S. Lagier. The threshold for event detection was set at twice the root-mean-square noise $(\sim 8 \mathrm{pA})$ and an experimenter blind to cell category analyzed all synaptic events. All other data were analyzed using custom-written code in Matlab.

\section{Regulation of candidate stem cell proliferation}

BrdU long-term labeling. For long-term labeling of candidate stem cells, 1 $\mathrm{mg} / \mathrm{ml}$ of the DNA synthesis marker 5-bromo-2'-deoxyuridine (BrdU; Sigma) was given to mice in their drinking water for 2 weeks. Mice were killed $26 \mathrm{~d}$ after the last day of BrdU treatment (40 d after treatment initiation), and brains were processed for immunohistochemistry.

Chemical ablation of olfactory epithelium. Mice were given intraperitoneal injections of dichlobenil (2,6-dichlobenzonitrile, $25 \mu \mathrm{g} / \mathrm{g}$ body weight; Fluka) in DMSO (dimethyl sulfoxide, $2 \mu \mathrm{l} / \mathrm{g}$ body weight) on days 0,2 , and 4 in parallel with BrdU administration. Mice were killed $26 \mathrm{~d}$ after the last day of BrdU treatment. The levels of chemical lesion in MOE tissues were evaluated based on the expression of olfactory marker protein (OMP) within the glomerular layer of the OB.

Enriched odor exposure. Mice were randomly assigned to two experimental groups. The enriched group consisted of animals housed in their home cages with an "odor pot" placed on the cage floor for 3 weeks. Common odoriferous items were used to enrich the olfactory environment (Table 2). Odor-enriched mice were exposed daily for $24 \mathrm{~h}$ to 3 different aromatic fragrances. Standard mice were reared under the same conditions except that the odor pot was left empty. Animals were allowed 
access to food and tap water ad libitum. After 1 week, tap water was removed and BrdU was given to mice in their drinking water for 2 weeks. Mice were killed $26 \mathrm{~d}$ after the last day of BrdU treatment.

Quantification of BrdU long-term labeling. For BrdU quantification, 1 in 3 slices along the mediolateral axis of the brain were selected in a systematic random manner in the left and right hemisphere to perform BrdU labeling. Apotome and epifluorescent mosaic images including the entire SVZ-RMS axis were obtained using a Plan-Neofluar $25 \times$ objective (NA 0.8) on an Apotome microscope (Zeiss; Aviovert 200M). On each section, all BrdU ${ }^{+}$cells were counted off-line using Apotome software (Axiovision 4.4; Zeiss). GFAP staining was used to draw up the boundaries of RMS and SVZ regions. Data are expressed as $\mathrm{BrdU}^{+}$cell number normalized to the sectional volume analyzed $\left(\mathrm{BrdU}^{+}\right.$cells $\left./ \mathrm{mm}^{3}\right)$ found in the SVZ, the RMS vertical limb (RMSvl, including RMS from the dorsal tip of the RMS up to the elbow) and the RMS elbow-horizontal limb (RMSelb$\mathrm{hl}$, including RMS elbow and the horizontal limb).

For double-staining analysis with GFAP and SOX2, stacks of $5 \mu \mathrm{m}$-thick optical slices were collected through the $z$-axis $(20-40 \mu \mathrm{m})$ of tissue sections of the analyzed regions. Colocalization was evaluated in single optical planes taken through the entire $z$-axis of each cell. For nontreated control animals, data are expressed as the percentage of double-labeled $\mathrm{BrdU}^{+} / \mathrm{GFAP}^{+}$cells and BrdU ${ }^{+} / \mathrm{SOX} 2^{+}$cells. For MOE-lesion and enrichment experiments, data are expressed as $\mathrm{BrdU}^{+} / \mathrm{GFAP}^{+}$cell number normalized to the sectional volume analyzed $\left(\mathrm{BrdU}^{+} / \mathrm{GFAP}^{+}\right.$cells $\left./ \mathrm{mm}^{3}\right)$ found in the SVZ and the entire RMS. Data from both control and standard conditions were pooled given that no differences in our results were found between these two groups. An experimenter blind to experimental conditions performed all quantitative analyses.

\section{Results}

Transducing glial cells with a Mokola lentiviral vector

To investigate whether astrocytes located in the RMS are candidate stem cells providing neural progenitors for adult circuits, we developed a method to label astrocytes and follow their progeny. We used a lentiviral vector designed to transduce glial cells with eGFP. Previous reports have shown that a Mokola-pseudotyped HIV can transduce oligodendroglia and astrocytes but not cultured hippocampal pyramidal neurons (Watson et al., 2002). We first checked that GFPencoding lentiviral vector particles pseudotyped with the Mokola envelope (hereafter referred to as the Mokola vector), indeed efficiently transduced mouse glial cells in vivo (Fig. 1). To completely rule out the possibility of transducing fast-dividing progenitors that might still express glial features, the antimitotic drug Ara-C was infused onto the brain surface for $6 \mathrm{~d}$ systematically before lentiviral injections (Fig. $1 A$ ). This treatment eliminates all dividing cells from the SVZ (Doetsch et al., 1999a,b) and

B

E
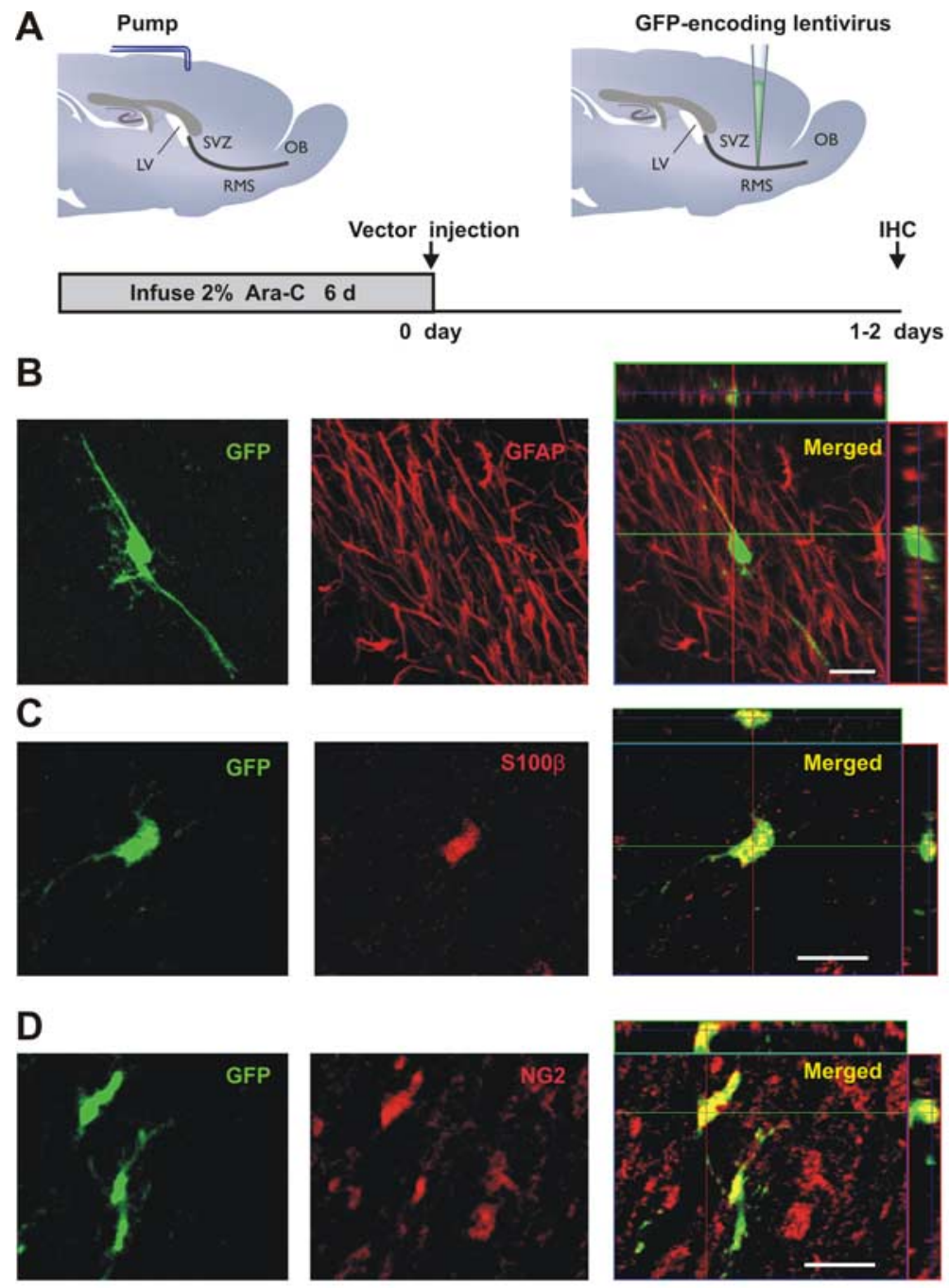

Figure 1. Identity of lentiviral-transduced cells in the RMS. A, GFP-encoding lentiviral vector, pseudotyped by the Mokola envelope, was injected into the RMS elbow of Ara-C treated mice. Animals were killed for analysis between 1 and $2 \mathrm{~d}$ postinjection (d.p.i.). $\boldsymbol{B}-\boldsymbol{D}$, Confocal micrographs showing infected cells at the injection site double-stained by immunofluorescence with GFP (green) and GFAP ( $\boldsymbol{B}$, red), S100B ( $\boldsymbol{C}$, red) or NG2 ( $\boldsymbol{D}$, red). Images represent the maximal projections of each individual channel (left and middle), and the orthogonal analysis in a single optical plane (right). $\boldsymbol{E}$, Quantitative analysis of double labeled cells detected at the injection site. Data are expressed as mean \pm SEM of the percentages of double-labeled cells with respect to the total amount of GFP-expressing cells (from 2 to 4 mice). The total numbers of GFP-labeled cells analyzed are indicated in brackets. Scale bars: $20 \mu \mathrm{m}$. IHC, immunohistochemistry; SVZ, subventricular zone; RMS, rostral migratory steam; $0 \mathrm{~B}$, olfactory bulb; LV, lateral ventricle; ND, not detected.

RMS (Gritti et al., 2002), but spares the population of quiescent astrocytes. After Ara-C treatment, scanning all SVZ and RMS sections with a confocal microscope confirmed the total elimination of fast-dividing precursors and neuroblasts. For instance, immunoreactivity for polysialic acid-neural cell adhesion molecule (PSA-NCAM, a marker of immature neurons) was absent in all of these analyzed regions (supplemental Fig. 1, available at www.jneurosci.org as supplemental material).

To confirm that the Mokola vector efficiently transduced glial cells in Ara-C-treated forebrains, coexpression with both glial and neuronal markers was analyzed at the injection site. After 
A
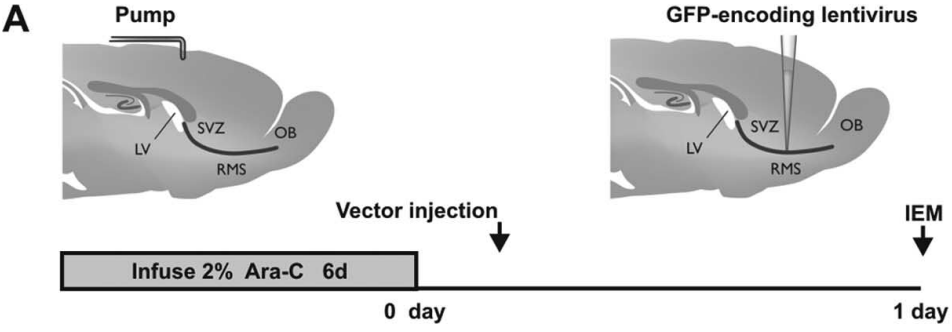

B
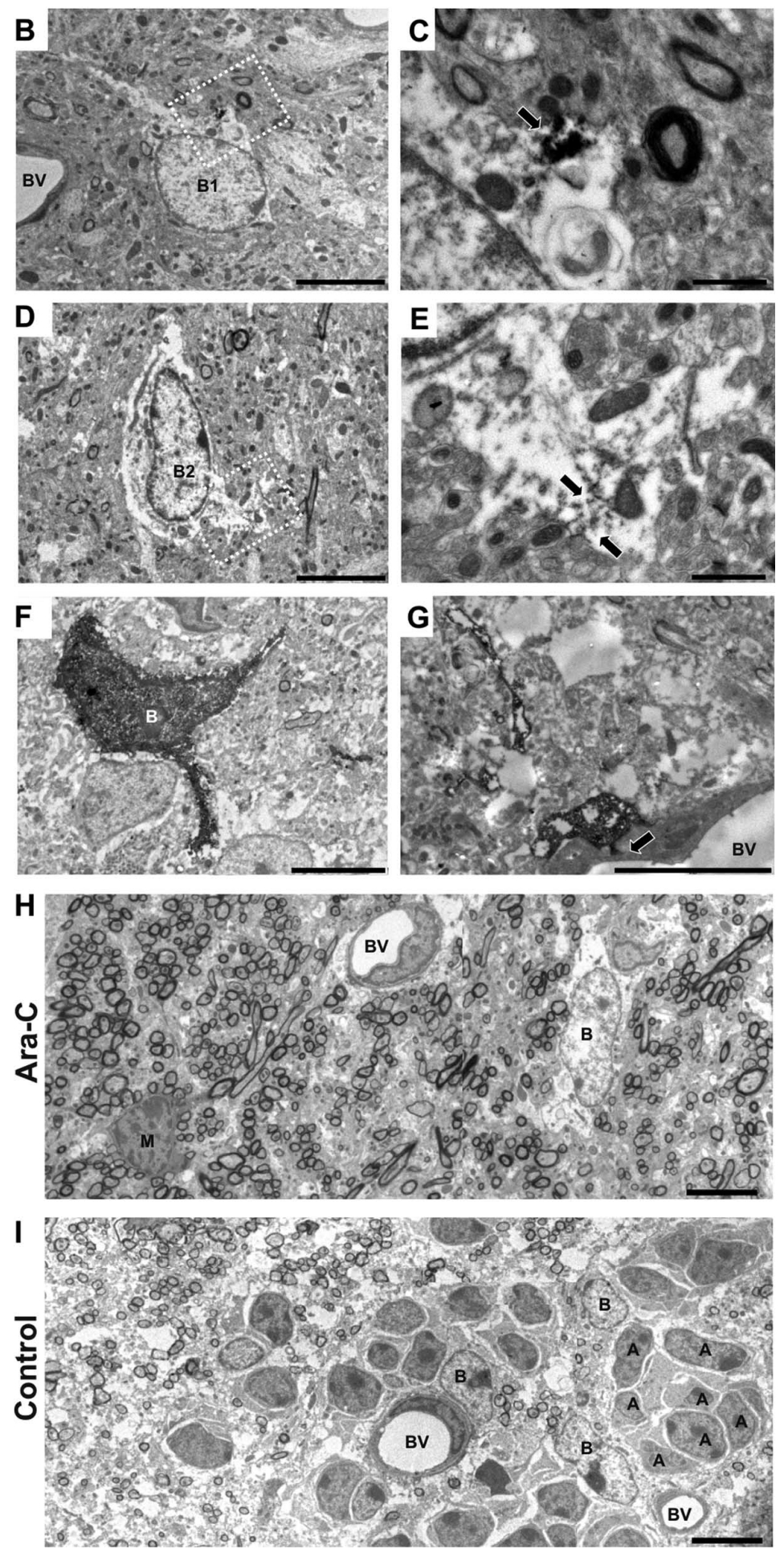

Figure 2. Identification of transfected cells by immunoelectromicroscopy. A, GFP-encoding Mokola vector was injected into the RMS elbow of Ara-C treated mice. Animals were killed for analysis at 1 d.p.i. B, D, GFP-expressing cells (B1, B2) showing light cytoplasm, irregular contours of cell surface and nonclumped chromatin typical for type-B1 astrocytes $(\boldsymbol{B})$ or clumped chromatin antimitotic treatment, the SVZ network can rapidly regenerate (Doetsch et al., 1999b). Thus, we killed animals at 1 or $2 \mathrm{~d}$ postinjection (d.p.i.), the minimal time required to reveal GFP in transduced cells without contamination by their progeny. To rule out the possibility that our vector could be transducing cells that had just started to divide after cessation of the Ara-C treatment, we measured the duration of activity of Mokola particles. Remarkably, only $2.4 \pm 0.9 \%(n=3)$ of the original titer could be detected after $24 \mathrm{~h}$ at $37^{\circ} \mathrm{C}$. The duration of vector infectivity does not therefore overlap with the SVZRMS regeneration that takes place after cessation of the Ara-C treatment (Doetsch et al., 1999b).

In these conditions, GFP staining was found to be colocalized: (1) with GFAP (a marker of mature astrocytes and of adult neural stem cells) (Fig. 1B), (2) with $\mathrm{S} 100 \beta\left(\mathrm{a} \mathrm{Ca}^{2+}\right.$-binding protein specifically expressed in some mature astrocytes) (Raponi et al., 2007) (Fig. 1C), and (3) with the proteoglycan NG2 (a marker of progenitors for oligodendrocytes) (Polito and Reynolds, 2005) (Fig. 1D). As expected, none of the $\mathrm{GFP}^{+}$cells expressed PSA-NCAM (Fig. 1E). When we injected the Mokola vector into the SVZ, GFP ${ }^{+}$ cells expressed only glial cell markers (data not shown), as seen in the RMS.

The glial tropism of the Mokola vector was further guaranteed by additional injections into areas hosting distinct neural cell populations. When vectors were directly injected into the $\mathrm{OB}$, none of the $\mathrm{GFP}^{+}$cells expressed markers for mature (NeuN for neuron-specific nuclear pro-

\footnotetext{
$\leftarrow$

typical for candidate stem cell type-B2 astrocytes (D). C, $\boldsymbol{E}$, Details of panels $B$ and $D$, respectively (white squares) showing examples of immunostaining of GFP in astrocyte cytoplasm. The electron dense precipitate of oxidized DAB was intentionally maintained at low intensity to facilitate ultrastructural identification of B astrocytes (arrows). F, GFPexpressing cell showing intentionally enhanced immunostaining of GFP in astrocytic cytoplasm. G, GFP-expressing cell showing typical astrocytic end foot apposed to the abluminal face of a blood vessel (arrow). $\boldsymbol{H}$, Panorama showing the ultrastructure of the RMS elbow $1 \mathrm{~d}$ after the end of Ara-C treatment (Ara-C). Chains of neuroblasts were not observed and only astrocytes $(\boldsymbol{B})$ could be detected. A mitotic figure is also shown $(\boldsymbol{M})$. $\boldsymbol{I}$, Panorama showing the ultrastructure of the RMS elbow in nontreated animals (Control) where chains of migrating neuroblasts $(\boldsymbol{A})$ interspersed with astrocyte-like glial cells $(\boldsymbol{B})$ are clearly distinguished. Magnification $1200 \times$ $(B, D, F), 5000 \times(C, E), 2000 \times(G), 800 \times(H, I)$. Scale bars: $5 \mu \mathrm{m}(\mathrm{B}, \mathrm{D}, \mathrm{F}-\mathrm{I})$ and $1 \mu \mathrm{m}(C, E)$. IEM, immunoelectron-microscopy; SVZ, subventricular zone; RMS, rostral migratory steam; OB, olfactory bulb; LV, lateral ventricle; BV, blood vessel.
} 
tein) or immature (PSA-NCAM) neurons. $\sim 14 \%$ of the $\mathrm{GFP}^{+}$cells were colabeled with GFAP (from 209 counted cells) (supplemental Fig. 2, available at www. jneurosci.org as supplemental material), whereas the rest of the infected glial cells were positive for $\mathrm{S} 100 \beta$ (77.2 $\pm 14.7 \%$, $n=2)$. Together, these results indicate that GFP-transduced cells are glial only.

To unambiguously characterize the $\mathrm{GFP}^{+}$cells, we analyzed Ara-C-treated forebrains with immunoelectronmicroscopy (IEM) at 1 d.p.i. (Fig. $2 A$ ). We performed pre-embedding immunostaining with antibodies against GFP and found transduced RMS-astrocytes. As previously shown, we distinguished at least two types of labeled astrocytes, B1 and B2 subtypes, according to their nuclear morphology. B2 cells have fewer free ribosomes and more clumped chromatin than B1 cells (Fig. $2 B$ $E$ ). The former type is thought to be a candidate stem cell in the SVZ (Doetsch et al., 1997). Identical results were obtained when a strong DAB reaction was performed (see Material and Methods) (Fig. $2 F)$. In addition, we found that some infected cells showed typical astrocytic end feet on blood vessels, as described previously (Peretto et al., 2005) (Fig. 2G). At a lower magnification, after Ara-C treatment, labeled cells with astrocytic features appeared scattered throughout the RMS (Fig. $2 \mathrm{H}$ ). In contrast, chains of migrating neuroblasts interspersed with astrocytelike glial cells could be seen in nontreated animals (Fig. 2I). Occasionally, we found type-C cells (also known as transitamplifying cells) that were distinguished from astrocytes by their deeply invaginated nucleus and absence of intermediate filaments (data not shown). Our confocal and IEM data therefore confirmed both the glial nature of cells infected by the Mokola vector, and the presence of specific cell types with neurogenic potential (i.e., type-B2 and type-C cells) in the RMS.

RMS-astrocytes continuously produce interneurons for the adult $\mathrm{OB}$ circuit We then focused on the cellular fate of $\mathrm{GFP}^{+}$cells generated in the RMS (Fig. $3 A$ ). To characterize the lineage of $\mathrm{GFP}^{+}$ glial cells, animals were killed at 21 or 90 d.p.i. to ensure sufficient time for proliferation, migration and differentiation. Twenty-one days after injecting $200 \mathrm{nl}$ of high titer Mokola lentiviral particles into the RMS, several $\mathrm{GFP}^{+}$cells were seen scattered in a large area ranging from the injection site to the OB. In the granule cell layer and the glomerular layer of the OB, newborn cells have morphological charac-
A
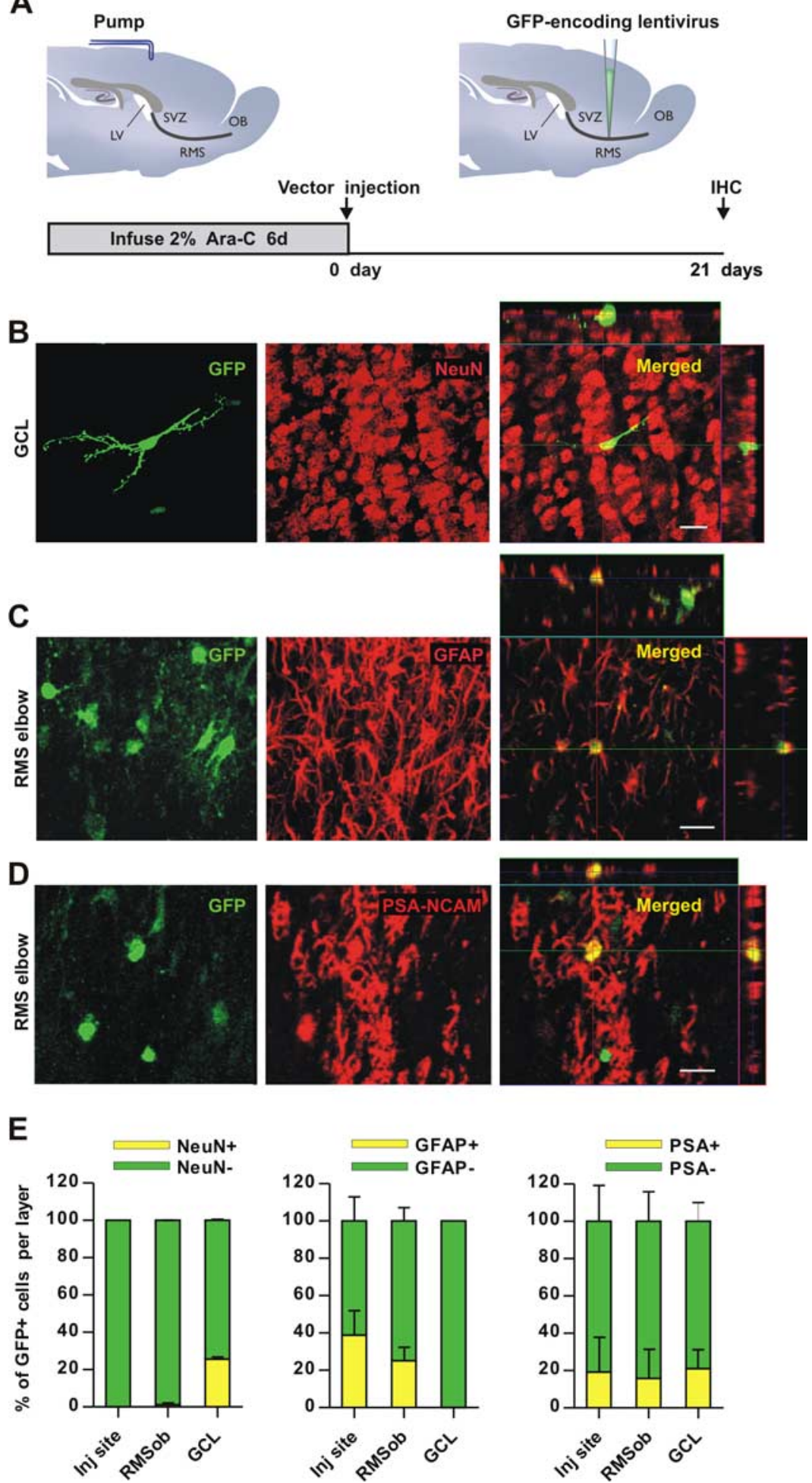

Figure 3. RMS-transduced cells generate newborn neurons in the adult OB. $\boldsymbol{A}$, Lentiviral vector, pseudotyped by the Mokola envelope, was injected into the RMS elbow of Ara-C treated mice. Animals were killed for analysis at 21 d.p.i. $\boldsymbol{B}-\boldsymbol{D}$, Confocal micrographs showing GFP-expressing cells (green) double-stained with the neuronal marker NeuN (B, red) in the granular cell layer (GCL) indicating that RMS-infected cells generate neurons in the OB in vivo. Infected astrocytes (green) reactive to GFAP (C, red) were still detected at the injection site (RMS elbow). Neuroblasts double-stained with GFP (green) and PSA-NCAM (D, red) were also found in the RMS elbow at 21 d.p.i. Images represent the maximal projections of each individual channel (left and middle), and the orthogonal analysis in a single optical plane (right). $\boldsymbol{E}$, Bar diagrams representing the percentage of doublelabeled cells (yellow) with respect to total number of GFP-expressing cells (green + yellow) from $n=2$ mice (total number of cells analyzed: 352, 223, 241 for NeuN, GFAP and PSA-NCAM, respectively). Scale bars: $20 \mu \mathrm{m}$. IHC, immunohistochemistry; SVZ, subventricular zone; RMS, rostral migratory steam; $O B$, olfactory bulb; LV, lateral ventricle; inj site, injection site; RMSob, rostral migratory stream entering the $O B$. 

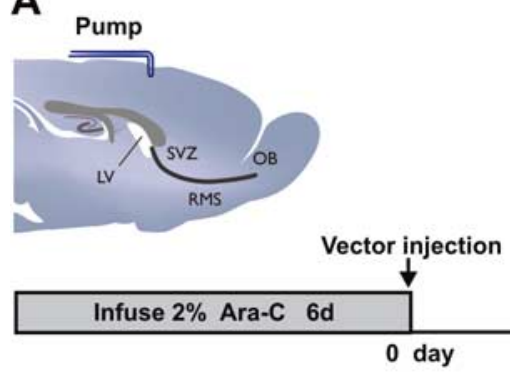

B
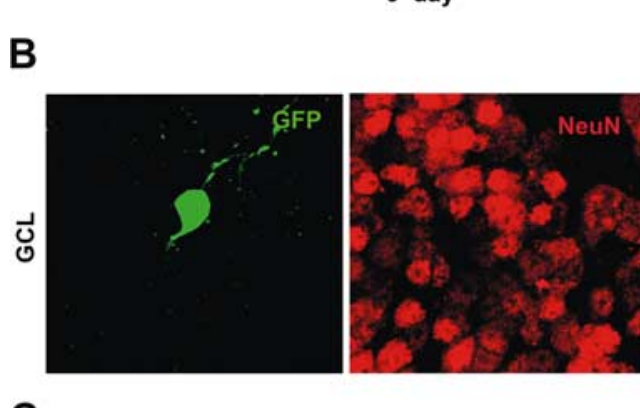

C

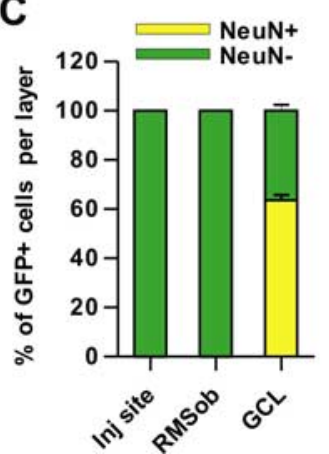

Infuse $2 \%$ Ara-C $6 d$

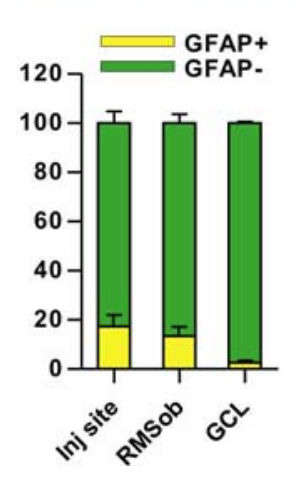

Alonso et al. • Regulation of Neural Stem Cell Proliferation in the RMS

GFP-encoding lentivirus
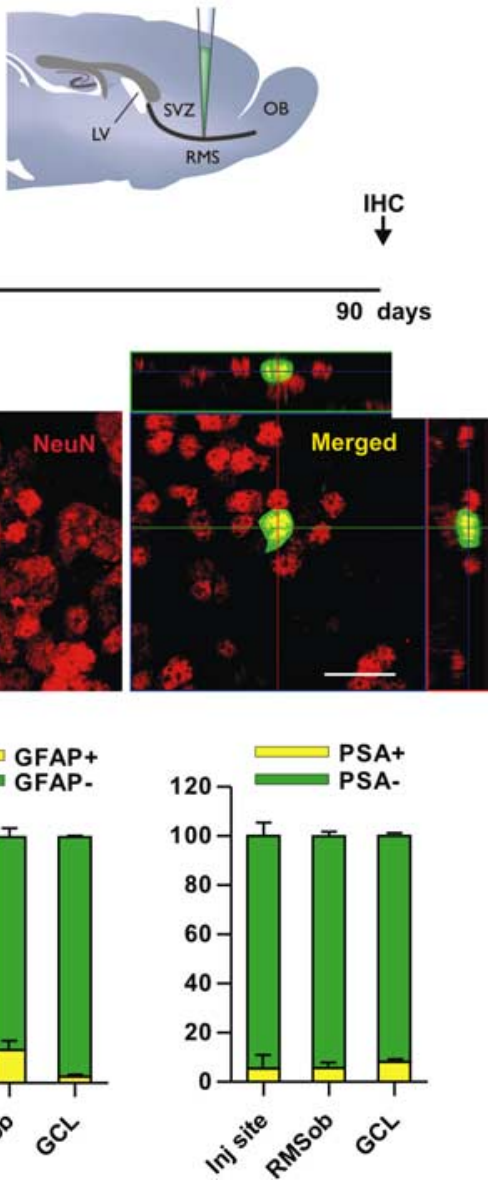

Figure 4. Neurogenic properties of the adult RMS. $A$, The Mokola vector was injected into the RMS elbow of Ara-C treated mice. Animals were killed for analysis at 90 d.p.i. B, Confocal micrographs showing GFP-expressing cells (green) in the GCL, doublestained with the neuronal marker NeuN (red). Images represent the maximal projections of each individual channel (left and middle), and the orthogonal analysis in a single optical plane (right). C, Bar diagrams representing the percentage of doublelabeled cells (yellow) with respect to the total number of GFP-expressing cells (green + yellow) from 2 mice (total number of cells analyzed: 907, 375 and 375 for NeuN, GFAP and PSA-NCAM, respectively). Scale bar: $20 \mu \mathrm{m}$. IHC, immunohistochemistry, SVZ, subventricular zone; $\mathrm{RMS}$, rostral migratory steam; $\mathrm{OB}$, olfactory bulb; $\mathrm{LV}$, lateral ventricle; $\mathrm{GCL}$, granule cell layer; inj site, injection site; RMSob, the rostral migratory stream entering the $O B$.

teristics of mature and immature granule (Fig. 3B) and periglomerular (supplemental Fig. $5 E, F$, available at www.jneurosci.org as supplemental material) neurons. Given that the vast majority of RMS-generated newborn cells are found in the granule cell layer (Batista-Brito et al., 2008), we then focused on this cell type.

Confocal analysis allowed us to identify the lineage of RMSproduced cells using double labeling with GFP and NeuN, GFAP or PSA-NCAM markers. NeuN staining that colocalized with GFP in the OB revealed the neuronal nature of RMS-generated newborn cells (Fig. $3 B, E$ ). In contrast, none of the $\mathrm{GFP}^{+}$cells were stained for GFAP in the granule cell layer, suggesting that RMS-astrocytes provide the $\mathrm{OB}$ with neurons only (Fig. $3 E$ ). In addition, Figure $3 C$ shows that, in the same animals, the $\mathrm{GFP}^{+}$ cells remaining in the injection site (i.e., the RMS elbow) share features with astrocytes (see also Fig. $3 E$ ). The presence of $\mathrm{GFAP}^{+}$cells in the RMS entering the OB (RMSob) suggests that infected cells are able not only to produce neurons, but also to contribute to the maintenance of the RMS-astrocytic population (Fig. 3E). Indeed, $21 \mathrm{~d}$ after Ara-C treatment, $\mathrm{GFP}^{+} / \mathrm{PSA}-$ $\mathrm{NCAM}^{+}$neuroblasts were detected in the RMS, consistent with transduced cells contributing to RMS regeneration (Fig. 3D,E).
To validate these results, we injected Mokola vectors into the SVZ (supplemental Fig. $3 A$, available at www.jneurosci.org as supplemental material). Newborn neurons (i.e., $\mathrm{GFP}^{+} / \mathrm{NeuN}^{+}$) were found only in the $\mathrm{OB}$ (supplemental Fig. $3 B, E$, available at www.jneurosci.org as supplemental material), whereas labeled astrocytes and neuroblasts were seen both in the injection site and in the RMS (supplemental Fig. $3 C, E$, available at www.jneurosci.org as supplemental material). Moreover, as we have shown previously (Hack et al., 2005), the percentage of labeled granule cells in the $\mathrm{OB}$ is lower when targeting injections into the RMS versus the SVZ (RMS: $83.0 \pm$ $0.3 \%$ and SVZ: $98.3 \pm 1.7 \%$ with respect to total labeled cells in the OB, $p<0.004$; Student's $t$ test, with two brains per group).

As expected if the Mokola vector transduces stem cells, $90 \mathrm{~d}$ after viral injection (Fig. 4A), we noted a threefold increase in the population of labeled newborn $\mathrm{OB}$ neurons at 90 d.p.i. compared with 21 d.p.i (from $25.6 \pm 0.6 \%$ to $63.6 \pm 2.5 \%$ of $\mathrm{NeuN}^{+}$cells with respect to the total number of $\mathrm{GFP}^{+}$cells in the granule cell layer, $p<0.005$, Student's $t$ test, with two brains per group) (Figs. $3 E, 4 B, C$ ). In addition, an increase in the total number of $\mathrm{GFP}^{+}$ cells present in the granule cell layer was observed between 21 and 90 d.p.i. (from $53 \pm 43-822 \pm 23, p<0.005$; Student's $t$ test, with two brains per group). These results indicate that the increase in the percentage of $\mathrm{NeuN}^{+}$cells observed between 21 and 90 d.p.i. cannot be explained by a simple delay in the maturation of newborn cells. Instead, they imply an accumulative effect, as expected for a continual production of new neurons from candidate stem cells.

To explore in more detail the potential multipotency of RMS stem cells, we used double labeling with both astrocyte and oligodendrocyte markers at 90 d.p.i. GFAP ${ }^{+}$cells were found not only in the injection site but also in the RMSob, suggesting that injected cells are producing not only neurons en route to the $\mathrm{OB}$ but also resident astrocytes in the RMS (Fig. 4C). This was reminiscent of our observations made at 21 d.p.i. A small proportion of $\mathrm{GFP}^{+}$cells were also stained with the astrocytic marker $\mathrm{S} 100 \beta$ ( $3.9 \pm 2.2 \%$ from 256 analyzed cell; two brains). However, the RMS is not involved in astrocytic production for the OB, given the negligible proportion of $\mathrm{GFP}^{+}$cells colabeled with GFAP $(2.55 \pm 0.55 \%$ from 276 analyzed cells, Fig. $4 C)$ or $S 100 \beta$ (0.7 \pm $0.7 \%$ from 231 analyzed cells; two brains) in this region. Even at 90 d.p.i., PSA-NCAM ${ }^{+}$neuroblasts continue to be detected in all analyzed regions, highlighting the continuous neuronal production from RMS-transduced cells (Fig. 4C).

To study the possible generation of oligodendrocytes from the $\mathrm{RMS} \mathrm{GFP}^{+}$cells, we analyzed the expression of NG2 (a marker of oligodendrocyte precursors) (Deloulme et al., 2004) and of O4 (a marker of mature oligodendrocytes) (Deloulme et al., 2004). At 90 d.p.i., only $7.2 \pm 0.5 \%$ (from 557 analyzed cells) of $\mathrm{GFP}^{+}$cells 

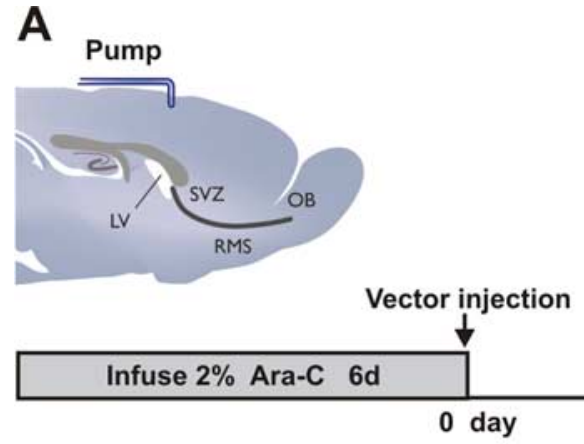

C

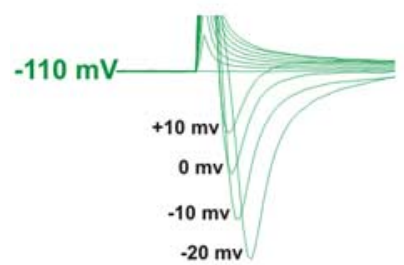

E GFP+
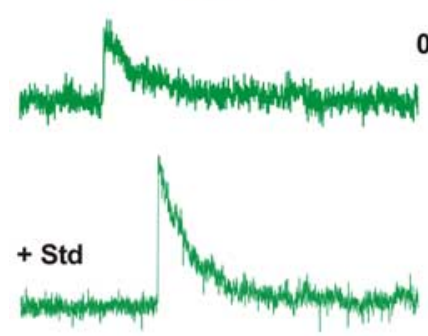

GABA events

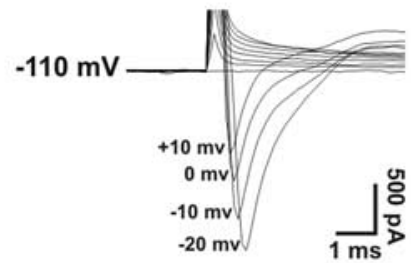

GFP-

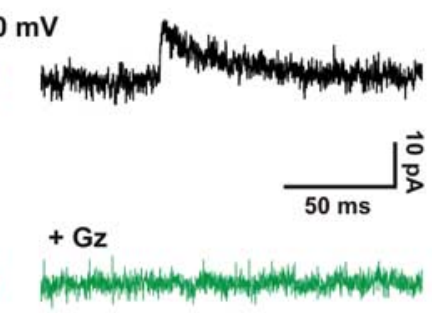

B
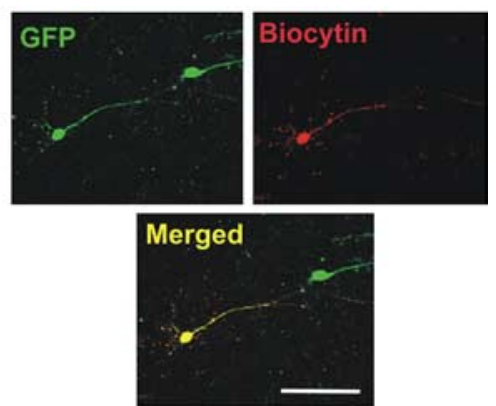

60 days

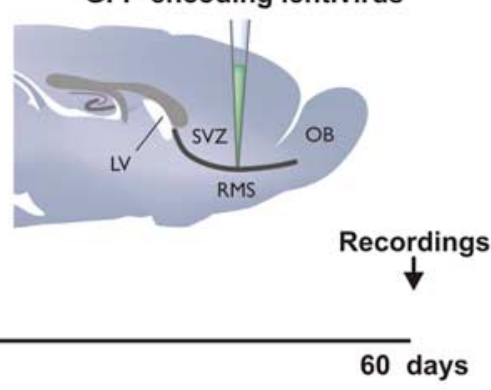

D

D GFP+

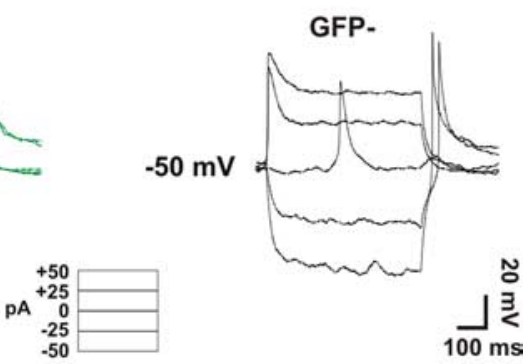

F

AMPA events

GFP+

GFP-

Figure 5. RMS-newborn cells become fully integrated neurons in the adult OB. $A$, The Mokola vector was injected into the RMS elbow of Ara-C treated mice. Animals were killed for analysis at 60 d.p.i. Electrophysiological whole-cell recordings from RMS-generated newborn (GFP ${ }^{+}$, in green) and preexisting granule cells (GFP ${ }^{-}$, in black) were performed in the granule cell layer from the same slices. B, Example of a GFP ${ }^{+}$cell (green) recorded and filled with biocytin (revealed by streptavidin-conjugated Alexa 568, red). Confocal images shown represent the maximal projections of each individual channel (top), and the merged projection indicating the presence of both green and red fluorescence in the patched cell (yellow, bottom). Scale bar: $50 \mu \mathrm{m}$. C, Example of voltage-dependent $\mathrm{Na}^{+}$current traces elicited by increasing depolarizing voltage steps (successive jumps of $10 \mathrm{mV}$ from $-110 \mathrm{mV}$ ) in both RMS-generated newborn (GFP ${ }^{+}$, in green) and preexisting granule cells (GFP ${ }^{-}$, in black). $\boldsymbol{D}, \mathrm{Na}^{+}$currents trigger spikes in current-clamp identically in both groups. Spikes are wide because voltage-gated potassium channels were blocked by our Cs-based intracellular solution, necessary for separate recording of glutamatergic and GABAergic synaptic inputs. E, Examples of traces of outward sIPSCs recorded from both groups (upper traces), and outward sIPSCs recorded in GFP ${ }^{+}$newborn cells in standard conditions (std) or in the presence of the GABA antagonist gabazine (Gz, $\left.10 \mu \mathrm{m}\right)$ (lower traces). Neurons were held at $0 \mathrm{mV}$, the reversal potential for glutamatergic events. $\boldsymbol{F}$, Examples of traces of inward sEPSCS recorded from both groups of cells (upper traces), and inward sEPSCS recorded in GFP ${ }^{+}$newborn cells in standard conditions (std) or in the presence of the AMPA antagonist NBQX (NBQX, $10 \mu \mathrm{M}$ ) (lower traces). Neurons were held at $-70 \mathrm{mV}$, the reversal potential for GABAergic events. Comparison between groups was performed by paired $t$ tests ( $n=6$ pairs). SVZ, subventricular zone; RMS, rostral migratory steam; $0 \mathrm{~B}$, olfactory bulb; $L V$, lateral ventricle.

in the RMSob were labeled with NG2. Similarly, $9.5 \pm 3.1 \%$ of $\mathrm{GFP}^{+}$cells (from 169 analyzed cells) were stained with $\mathrm{O} 4$ (data not shown). $\mathrm{RMS} \mathrm{GFP}^{+}$cells generated only a small proportion of oligodendrocytic cells in the $\mathrm{OB}\left(\mathrm{GFP}^{+} / \mathrm{NG} 2^{+}\right.$double-stained cells in the granular cell layer: $1.6 \pm 0.6 \%$ of total $\mathrm{GFP}^{+}$cells, from 238 analyzed cells, and GFP ${ }^{+} / \mathrm{O}^{+}: 6.1 \pm 2.4 \%$, from 562 analyzed cells). These results confirm and extend the notion that the adult RMS is a neurogenic area. Not only does it supply the OB circuit with newborn neurons, it also produces a small proportion of local astrocytes and oligodendrocytes in the GCL.

\section{RMS-derived progenitors become functionally integrated} OB neurons

Having established that RMS-generated newborn cells develop morphological and immunocytochemical neuronal characteris- tics, we examined whether transduced glial cells also acquire the electrophysiological hallmarks of neurons and, if so, whether they become functionally integrated into the $\mathrm{OB}$ network. In particular, we investigated whether they acquire functional properties of local inhibitory interneurons, similar to those of their (presumably mature) preexisting neighbors. At 60 d.p.i., expression of GFP was detected using fluorescence microscopy, and positive cells in horizontal $\mathrm{OB}$ slices were then targeted for patchclamp recordings (Fig. 5A). Adjacent nonlabeled interneurons were used as fully mature local interneuron controls from the same slices. Double label of targeted cells with GFP and either rhodamine (immediate) or biocytin (postfixation) from the patch pipette confirmed the RMS-born identity of our recorded neurons (Fig. 5B). Passive membrane properties were estimated from responses to a $10 \mathrm{mV}$ voltage step (see Materials and Meth- 
A

\begin{tabular}{|l|l|l|l|l|}
\hline BrdU in drinking water & IHC \\
\hline 0 day & 15 days & 41 days
\end{tabular}
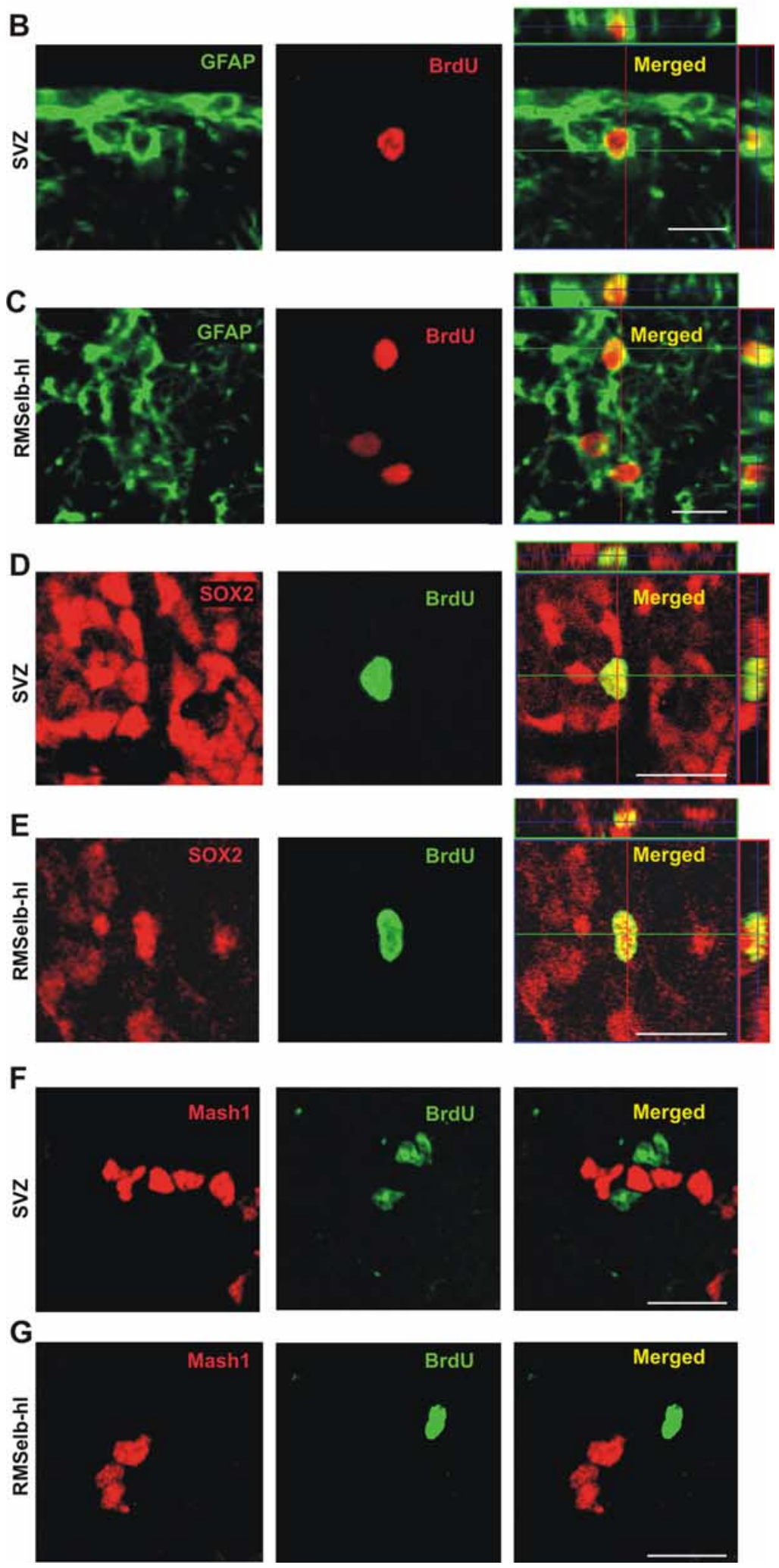

Figure 6. Candidate stem cells are present in the adult RMS. A, For long-term labeling of candidate stem cells, BrdU $(1 \mathrm{mg} / \mathrm{ml})$ was given to mice in their drinking water for 2 weeks. Animals were killed for analysis $26 \mathrm{~d}$ after the end of the treatment (day 41 ), giving sufficient time post-BrdU to allow the fast-dividing type-C cell population to be washed out, and for the neuroblasts in the ods), and did not differ significantly between $\mathrm{GFP}^{+}$cells and nonlabeled interneurons $\left(\mathrm{R}_{\text {input }}: \mathrm{GFP}^{+} 867.9 \pm 182.6 \mathrm{M} \Omega\right.$ and $\mathrm{GFP}^{-} 875.9 \pm 105.2 \mathrm{M} \Omega$, $t$ test, $p=$ $0.97 ; \mathrm{C}_{\mathrm{m}}: \mathrm{GFP}^{+} 13.6 \pm 1.9 \mathrm{pF}$ and $\mathrm{GFP}^{-}$ $10.2 \pm 0.7 \mathrm{pF}, t$ test; $p=0.15)$. Voltagegated active sodium currents were also indistinguishable in RMS-born and control cells (peak amplitude of $\mathrm{Na}^{+}$currents obtained after stepping to $-20 \mathrm{mV}: 1.88 \pm$ 0.31 and $2.07 \pm 0.37 \mathrm{nA}$ for $\mathrm{GFP}^{+}$and $\mathrm{GFP}^{-}$, respectively, $p=0.5758$ ) (Fig. $5 C$ ), strongly suggesting that newborn interneurons are as excitable as their nonlabeled neighbors. This was confirmed by current-clamp recordings showing similar spiking activity between $\mathrm{GFP}^{+}$cells and nonlabeled interneurons (Fig. 5D) $(n=15$ $\mathrm{GFP}^{+}$and $11 \mathrm{GFP}^{-}$cells). Sodium current identity was confirmed by TTX application $(1 \mu \mathrm{M})$, which completely abolished both the inward sodium current and spiking behavior in both cell groups (data not shown; $n=10$ cells).

When afferent connectivity was examined, both inhibitory (Fig. $5 E)(n=16$ $\mathrm{GFP}^{+}$and $11 \mathrm{GFP}^{-}$cells) and excitatory (Fig. $5 F)\left(n=17 \mathrm{GFP}^{+}\right.$and $12 \mathrm{GFP}^{-}$ cells) synaptic events exhibited similar properties (amplitude, kinetics and frequency) in the two cell groups (GABA events: sIPSCs peak amplitude $17.50 \pm$ 3.38 and $16.73 \pm 2.94 \mathrm{pA}$ for $\mathrm{GFP}^{+}$and $\mathrm{GFP}^{-}$cells, respectively, $p=0.9811$, and inter-event interval (IEI) $2658 \pm 626$ and $2589 \pm 826 \mathrm{~ms}$ for $\mathrm{GFP}^{+}$and $\mathrm{GFP}^{-}$cells, respectively, $p=0.7078$; AMPA events: sEPSCs peak amplitude $11.05 \pm 0.90$ and

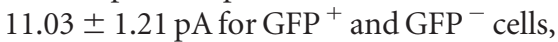
respectively, $p=0.6824$, and IEI $1165 \pm$ 217 and $2087 \pm 847 \mathrm{~ms}$ for $\mathrm{GFP}^{+}$and $\mathrm{GFP}^{-}$cells, respectively, $p=0.3411$ ). The

\footnotetext{
$\leftarrow$

RMS to reach the $O B$ (Lemasson et al., 2005). B, C, Confocal micrographs showing candidate stem cells double-stained with GFAP (green) and BrdU (red) in the SVZ (B) and in the region including the RMS elbow and the horizontal limb (RMSelb-hl, C). Images shown represent the maximal projections of each individual channel (left and middle), and the orthogonal analysis in a single optical plane (right). $\boldsymbol{D}, \boldsymbol{E}$, Confocal micrographs showing candidate stem cells doublestained with SOX2, a marker of stem cells (red), and BrdU (green) in the same regions as boxed in B-C. Images show the maximal projections of each individual channel (left and middle), and the orthogonal analysis in a single optical plane (right). $\boldsymbol{F}, \mathbf{G}$, Confocal micrographs showing cells stained with Mash1 (red), a marker for type-C cells, and BrdU (green) in the same regions as specified in $\boldsymbol{B}, \boldsymbol{C}$. Images shown represent the maximal projections of each individual channel (left and middle), and the merged projection (right). Scale bars: $20 \mu \mathrm{m}$. IHC, immunohistochemistry; SVZ, subventricular zone; RMS, rostral migratory steam; $\mathrm{OB}$, olfactory bulb; LV, lateral ventricle.
} 
identity of both GABA and AMPA currents measured from RMSgenerated newborn cells was confirmed by the bath application of specific blockers (Fig. 5E,F) $(n=13$ cells treated with gabazine and 6 with NBQX). Finally, as mentioned above, the RMS also generates periglomerular cells in the glomerular layer of the OB. When these cells were recorded, we also found the presence of spikes in current-clamp ( 5 of 6 cells), as well as inhibitory ( 7 of 7 cells) and excitatory ( 6 of 7 cells) synaptic events that were all blocked by their respective inhibitors (supplemental Fig. $5 A-D$, available at www.jneurosci.org as supplemental material). These results therefore demonstrate that at 60 d.p.i., newly generated interneurons derived from RMS-astrocytes acquire functional membrane properties and incorporate into existing circuits, making them indistinguishable from preexisting granule and periglomerular cells.

\section{Chemical ablation of the MOE increases proliferation of RMS candidate stem cells}

Having established that RMS-astrocytes could provide the OB with genuine olfactory interneurons, we next investigated whether the proliferation of RMS candidate stem cells could be regulated. We first established a protocol to accurately quantify the proliferation of slowly dividing cells after different treatments. In several regions, including the SVZ, the slowly dividing, label-retaining cells correspond to a population of resident stem cells (Jackson et al., 2006; Sakaguchi et al., 2006). To detect this cell population in the RMS, BrdU was administered for 2 weeks via drinking water. Mice were then killed $26 \mathrm{~d}$ later (Fig. 6 A). This delay allowed the BrdU in the fast dividing type-C cell population to be washed out and the neuroblasts in the RMS to reach the OB (Lemasson et al., 2005). BrdU ${ }^{+}$cells were found not only in the SVZ (Fig. $6 B$ ) but also throughout rostral regions including the RMS elbow (Fig. 6C). We stained for GFAP to characterize $\mathrm{BrdU}^{+}$cells (Fig. 6B,C). Because the GFAP signal is localized to processes, it is difficult to colocalize GFAP with nuclear BrdU staining. However, we could be certain that at least $21.6 \pm 4.2 \%$ of BrdU ${ }^{+}$cells in the SVZ, $24.7 \pm 2.2 \%$ of $\mathrm{BrdU}^{+}$cells in the RMSvl and $28.7 \pm 1.9 \%$ of BrdU ${ }^{+}$cells in the RMSelb-hl, were also $\mathrm{GFAP}^{+}(n=6,861$ cells $)$. In addition, $58.2 \pm 3.1 \%$ of $\mathrm{BrdU}^{+}$cells in the SVZ, $59.9 \pm 3.3 \%$ of $\mathrm{BrdU}^{+}$cells in the RMSvl, and $49.2 \pm 3.8 \%$ of BrdU ${ }^{+}$cells in the RMSelb-hl $(n=3$, 598 cells) were labeled with the transcription factor SOX2 (Fig. $6 D, E$ ), another marker of neural stem cells (Ferri et al., 2004). These data validate our protocol aimed at effective labeling of candidate stem cells. Moreover, positive cells for Mash1 ${ }^{+}$(a proneural transcription factor used here as a marker of type- $C$ cells) were also detected in all these regions forming clusters next to $\mathrm{BrdU}^{+}$candidate stem cells (Fig. $6 F, G$; supplemental Fig. $4 B$, available at www.jneurosci.org as supplemental material). This strongly suggests the presence of type-C cells in the RMS, as we observed with electronic microscopy (data not shown).

To check whether cell proliferation in the adult RMS is sensitive to lesions in the olfactory system, we first sought to challenge functional connections from the MOE to the OB. For this, we combined the long-term BrdU labeling protocol with injections of dichlobenil to temporarily ablate the MOE (Fig. 7A). Dichlobenil is an olfactotoxin that selectively ablates the MOE, producing clear effects at histological and behavioral levels (Vedin et al., 2004; Yoon et al., 2005). To confirm the efficiency of our treatment, OMP staining was performed to label the axons of olfactory sensory neurons. Two weeks after starting the dichlobenil treatment, OMP staining dramatically decreased in the olfactory nerve layer of the $\mathrm{OB}$, and disappeared in glomeruli (Fig. $7 B$ ).
This effect was reversible, because complete OMP staining recovery was seen 6 weeks after treatment (data not shown). We found that the loss of the MOE increased the density of $\mathrm{BrdU}^{+}$cells (drug: $F_{(1,30)}=9.765, p=0.0039$; region: $F_{(2,30)}=2.804, p=$ 0.0765 , not significant; drug by region: $F_{(2,30)}=1.759, p=$ 0.1895 , not significant) although this increase was significant exclusively in the most rostral part of the RMS (RMSelb-hl) (Fig. $7 C, D)$. No differences were seen in cell proliferation in the SVZ (Fig. 7D). Thus, our lesion protocol revealed that cell proliferation can be upregulated in a restricted region of the most rostral part of the RMS.

\section{An enriched olfactory environment increases proliferation of candidate stem cells in the SVZ and RMS}

Because the ablation of the MOE constitutes a rather drastic manipulation, we sought a more realistic condition in which RMS proliferation could be regulated. Thus, to investigate the potential physiological relevance of the presence of neural stem cells in the RMS, we challenged the overall degree of olfactory experience. Several studies have shown that the degree of global olfactory sensory input regulates the survival of newborn neurons in the OB (Corotto et al., 1994; Petreanu and Alvarez-Buylla, 2002; Rochefort et al., 2002; Miwa and Storm, 2005; Saghatelyan et al., 2005; Yamaguchi and Mori, 2005), but not proliferation of fastdividing cells in the SVZ (Rochefort et al., 2002; but see Mandairon et al., 2003; Magavi et al., 2005). We kept mice in standard conditions or in an odor enriched environment for 3 weeks in combination with the long-term BrdU labeling protocol (Fig. $8 A$ ). We found that daily exposure to different odors for 3 weeks strongly increased the density of $\mathrm{BrdU}^{+}$cells in both the vertical (RMSvl) and the elbow-horizontal limb (RMSelb-hl) of the RMS, and in the SVZ (treatment: $F_{(1,30)}=55.37, p<0.0001$; region: $F_{(2,30)}=5.281, p=0.0108$; drug by treatment: $F_{(2,30)}=1.517$, $p=0.2357$, not significant) (Fig. $8 B-D$ ). Our results thus demonstrate that the proliferation of slowly dividing cells in the RMS and in the SVZ can be regulated by the overall degree of olfactory sensory input.

Similar results were found after enrichment and MOE-lesion when $\mathrm{BrdU}^{+} / \mathrm{GFAP}^{+}$double-labeled cells were quantified (treatment: $F_{(2,42)}=9.965, p=0.0003$; region: $F_{(1,42)}=14.17$, $p=0.0005$, treatment by region: $F_{(2,42)}=0.3409, p=0.7131$, not significant; Bonferroni post-test: Control vs enriched group: SVZ, $p<0.05$; RMS, $p<0.01$; Control vs Dichlo-treated animals: SVZ, $p>0.05$, not significant; RMS, $p<0.05$; two-way ANOVA, $n=6-12$ ) strongly suggesting that both treatments increase candidate stem cell proliferation in the RMS.

\section{Discussion}

This study demonstrates that RMS-astrocytes constitutively generate functionally integrated $\mathrm{OB}$ interneurons, along with glial cells that remain in the RMS itself. The neurogenic zone of the forebrain therefore comprises a large extended area, starting from the SVZ and ending in the core of the adult OB. We also show that the proliferation of candidate neural stem cells in the RMS is sensitive to both lesions of the olfactory epithelium, and the amount of olfactory sensory input reaching the OB.

\section{Revealing proliferating astrocytes in the adult RMS}

Taking advantage of an appropriate Mokola GFP-encoding lentiviral vector combined with antimitotic treatment, we targeted quasi-quiescent RMS-astrocytes to characterize their progeny. Confocal and electronic microscopy analyses confirmed the glial nature of the transduced cells. Although $\mathrm{GFAP}^{+}, \mathrm{S}_{100 \mathrm{~B}^{+}}$and 
A

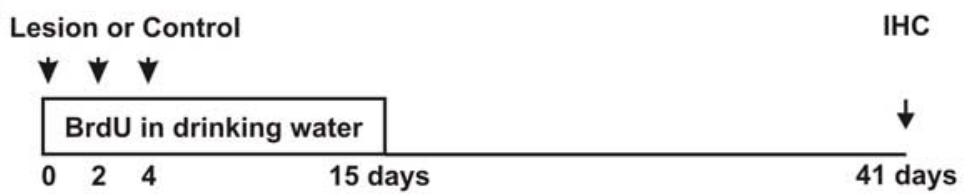

B

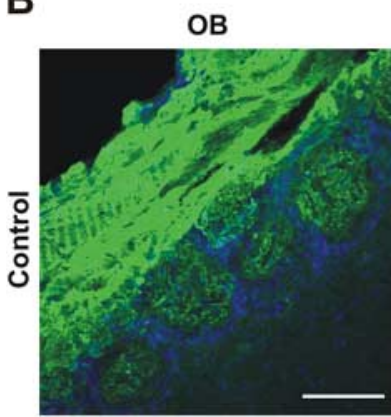

C

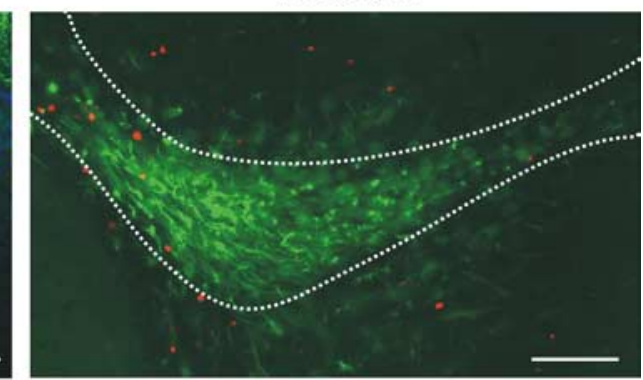

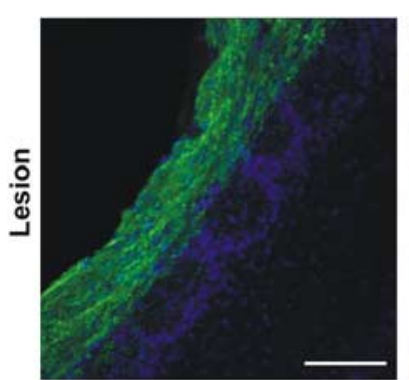

ОМР/TOTO

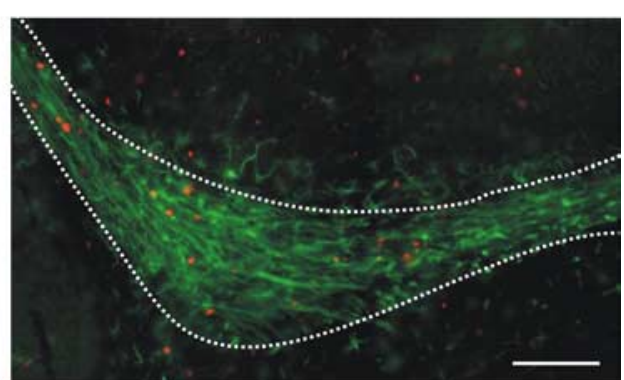

BrdU/GFAP

$$
\text { D }
$$

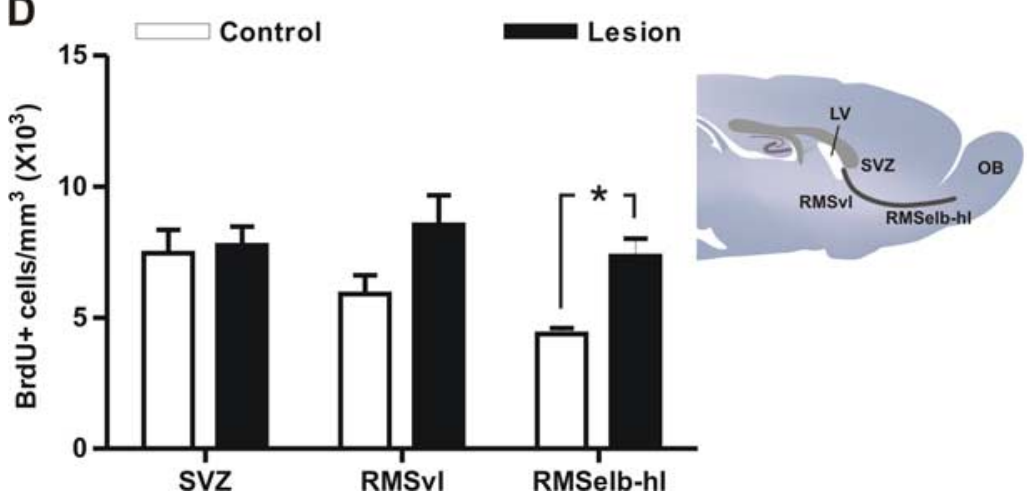

Figure 7. Temporary chemical lesion of the MOE increases candidate stem cell proliferation in the RMS. $\boldsymbol{A}$, To study the effect of chemical ablation of the main olfactory epithelium (MOE) on candidate RMS-stem cell proliferation, mice were given i.p. injections of either dichlobenil (lesion; $25 \mu \mathrm{g} / \mathrm{g}$ body weight) or DMSO (control) on days 0, 2, and 4 in parallel with BrdU labeling. Animals were killed for analysis $26 \mathrm{~d}$ after the end of the treatment (day 41). $\boldsymbol{B}$, To assess the lesion of the M0E, olfactory marker protein (OMP) staining (green) was analyzed in both DMSO controls (top) and dichlobenil-injected mice (Lesion, bottom). Examples of OMP staining 2 weeks after the beginning of the treatment are shown. Slices were counterstained with TOTO (blue) to reveal the glomerular structure. C, Fluorescent images showing examples of BrdU ${ }^{+}$candidate stem cells (red) in the RMSelb-hl in both DMSO controls (top) and dichlobenil-treated mice (Lesion, bottom). The boundary of the analyzed region is outlined in white and is based on GFAP staining. Confocal images shown represent the maximal projections of merged channels. $D$, Chemical ablation of the MOE in dichlobenil-treated animals (Lesion) increased the number of BrdU-labeled cells in the RMS elbowhorizontal limb (RMSelb-hl) without affecting the subventricular zone (SVZ) or the RMS vertical limb (RMSvl). Comparison between treatments was performed by Bonferroni post-test after two-way ANOVA ( $n=6$ per group). ${ }^{*} p<0.05$. Scale bars: 100 $\mu \mathrm{m}$. IHC, immunohistochemistry; LV, lateral ventricle.

$\mathrm{NG}^{+}{ }^{+}$cells were transduced by the lentiviral particles, only $\mathrm{GFAP}^{+}$astrocytes generate newborn neurons. $\mathrm{S} 100 \beta$ expression defines a late developmental stage after which astrocytes lose their stem cell potential (Raponi et al., 2007). $\mathrm{NG} 2^{+}$cells have multiple roles early in development (Aguirre and Gallo, 2004), and also generate oligodendrocytes (Polito and Reynolds, 2005), but never produce neuronal progeny in the adult brain. In addition, recent in vitro data support the notion that $\mathrm{NG}^{+}$cells function as oligodendrocyte precursors, and that $\mathrm{GFAP}^{+} /$nestin $^{+}$and NG2 ${ }^{+}$cells represent different populations of progenitors in the adult CNS (Jiao and Chen, 2008). Our ultrastructural observations reveal the presence of type-B2 astrocytes and type- $C$ cells in the RMS. Existence of type- $C$ cells in the RMS was also confirmed by Mash1 staining (supplemental Fig. 4, available at www.jneurosci.org as supplemental material), suggesting the presence of an entire neurogenic niche in the RMS, at variance with previous electron-microscopy studies (Doetsch et al., 1997).

Twenty-one days after injecting Mokola vectors into the RMS, GFP ${ }^{+}$cells expressing markers of mature neurons were seen in the OB. At the same time, $\mathrm{GFP}^{+}$astrocytes were detected at the injection site of the same animals, probably including self-renewing candidate stem cells. Accordingly, $\mathrm{GFP}^{+}$neuroblasts were also found in the RMS, supporting the notion of constitutive neuronal production by the transduced RMS-astrocytes. It is important to underline here that these data were not exclusively collected under regenerative conditions. For instance, at 21 d.p.i., ongoing cell production by RMSlabeled stem cells is occurring when the mitotic inhibitor has been already washed out and when complete regeneration of the normal SVZ structure has been demonstrated (Doetsch et al., 1999b). Because our vector labels slowly dividing cells that are continuously producing newborn $\mathrm{OB}$ interneurons, a heterogeneous population of new neurons was found in the GCL at any given time point after injection. Newborn cells never express PSA-NCAM and NeuN simultaneously (for review, see Lledo et al., 2006), so there may be intermediate maturation states in which PSANCAM expression has vanished but NeuN expression is still undetectable. This could explain why summing $\mathrm{PSA}^{+}$and $\mathrm{NeuN}^{+}$ cells after Mokola vector injections gave only 50 and $70 \%$ of the total $\mathrm{GFP}^{+}$cells in the GCL at 21 and 90 d.p.i., respectively. Of course, we cannot completely rule out that, in addition to neurons and the small proportion of astrocytes and oligodendrocytes detected, RMS-astrocytes also generate an as-yet unidentified cell population. Further experiments are required to fully characterize the potential of this neurogenic region. In summary, our results confirm that the SVZ and RMS both provide new neurons for the adult OB. In addition, they show that the RMS can sustain neuronal production in normal conditions, because a clear cumulative effect was seen between 21 and 90 d.p.i. 


\section{The RMS and SVZ form distinct} neurogenic niches

Transplantation studies have defined neurogenic and non-neurogenic brain regions, and have shown that the microenvironment can influence the potentialities of neural precursors. Precursor cells transplanted into neurogenic regions can differentiate into neurons in a region-specific manner. For example, precursor cells taken from the hippocampus generate $\mathrm{OB}$ interneurons when transplanted into the RMS, generating only glia outside neurogenic regions (Suhonen et al., 1996). The RMS therefore offers a permissive microenvironment for adult neurogenesis, and contains nesting neural precursor cells capable of cell division and neuronal commitment.

Our results fully support and extend results from Merkle et al. (2007) showing that progenitors located in the RMS can give rise in vivo to $\mathrm{OB}$ neurons with the morphological and biochemical characteristics of mature interneurons. Permanent suppression of SVZ neurogenesis induces a transient but remarkable ability for maintenance of the bulbar interneuron population although this capacity fails dramatically beyond one year (Panagiotakos et al., 2007). This indicates that the self-renewal of neural precursors in the RMS lacks long-term capacity, at least when inactivating the neurogenic potential of SVZ. This observation also supports the notion of heterogeneity among adult neural stem cells (Merkle et al., 2007). Our present results are certainly consistent with such heterogeneity, showing that a larger percentage of periglomerular neurons, as compared with granule cells, are produced by stem cells located in the RMS compared with the SVZ. Additional experiments should employ targeted in vivo ablations to probe the quantitative contributions of RMS- versus SVZ-generated neurons in the adult $\mathrm{OB}$.

After the postnatal closure of the olfactory ventricle, only the middle/posterior part of the SVZ remains in contact with the ventricles. Such histological compartmentalization might be at the origin of the differences in stem cell self-renewal and its regulation. Also, an emerging element of stem cell niche segregation is the close association with endothelial cells forming blood vessels, which regulates stem cell self-renewal and differentiation (Alvarez-Buylla and Lim, 2004). Between the SVZ and RMS, the blood-derived factors could act distinctly. Interestingly, we found close contacts of RMS-infected astrocytes with blood vessels (Fig. $2 G$ ) suggesting the potential regulation of candidate stem cell proliferation or commitment by vascular derived factors (Shen et al., 2004).

A

B

D

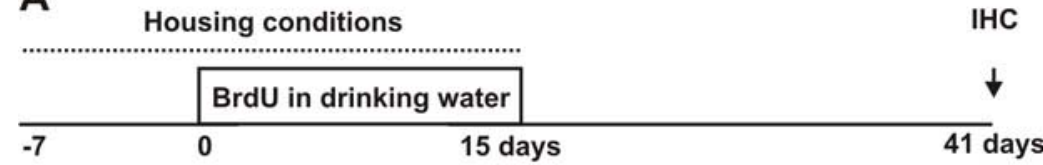

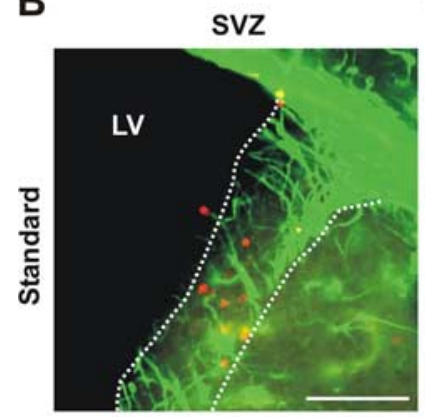

C RMSelb-hl

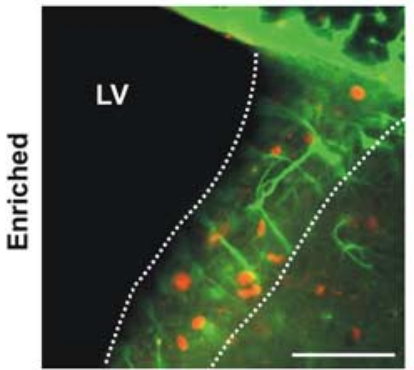

BrdU/GFAP
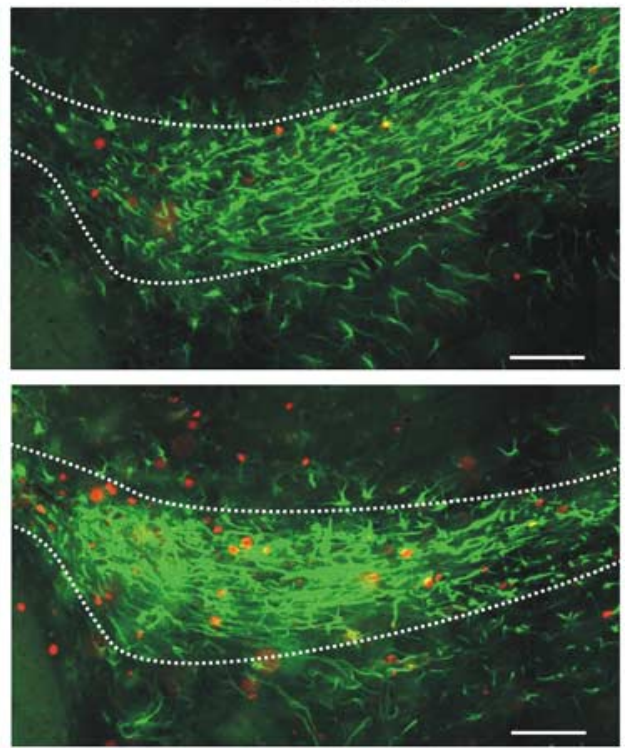

BrdU/GFAP

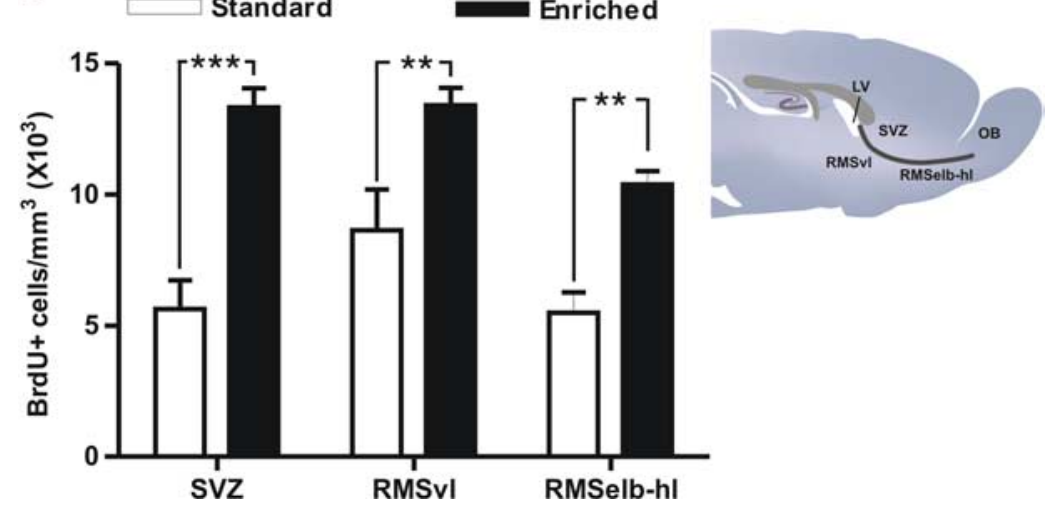

Figure 8. Enriched odor exposure increases candidate stem cell proliferation in the SVZ and RMS. A, Mice were kept in standard conditions or in an enriched odor environment for 3 weeks. After 1 week normal tap water was replaced by BrdU $(1 \mathrm{mg} / \mathrm{ml})$ in their drinking water for 2 weeks. Animals were killed for analysis $26 \mathrm{~d}$ after the end of the treatment (day 41). B, C, Fluorescent images showing examples of $\mathrm{BrdU}^{+}$candidate stem cells (red) and in the subventricular zone SVZ (B) and in the elbow-horizontal limb (RMSelb-hl) of the RMS ( $C$ from standard (top) and enriched mice (bottom). The boundary of the analyzed region is outlined in white and is based on GFAP staining. Confocal images shown represent the maximal projections of merged channels. $\boldsymbol{D}$, In enriched mice, the number of BrdU-labeled cells is increased in both the vertical (RMSvl) and the RMSelb-hl of the RMS and in the SVZ regions. Comparison between treatments was performed by Bonferroni post-test after two-way ANOVA ( $n=6$ per group). ${ }^{* *} p<0.01,{ }^{* * *} p<0.001$. Scale bars: $50 \mu \mathrm{m}$. IHC, immunohistochemistry; LV, lateral ventricle.

Our electrophysiological experiments demonstrate that newborn cells generated in the RMS do acquire functional membrane properties and integrate into existing neuronal networks within the adult $\mathrm{OB}$ circuit, making them indistinguishable from preexisting local interneurons at 60 d.p.i. However, because we have focused our electrophysiological analysis on functionally mature $\mathrm{GFP}^{+}$neurons, specific characteristics of adult newborn neurons might emerge at immature stages (Carleton et al., 2003; Espósito et al., 2005; Grubb et al., 2008). 


\section{Specific regulation of neural stem cell proliferation}

The continuous replacement of neurons in the OB may allow for the adjustment of olfactory circuitry as the environment or relevance of odorants continuously changes. Here we show that olfactory enrichment increases cell proliferation in vivo, demonstrating that SVZ-RMS cell proliferation is indeed sensitive to the degree of sensory experience. Although the survival of adultgenerated neurons is believed to be the main target of sensory experience (Corotto et al., 1994; Petreanu and Alvarez-Buylla, 2002; Rochefort et al., 2002; Miwa and Storm, 2005; Saghatelyan et al., 2005; Yamaguchi and Mori, 2005), our data reveal that the production of new neurons is susceptible to experience-induced regulation. At first glance, these appear to contradict previous results, which reported no change in SVZ cell proliferation after olfactory enrichment (Rochefort et al., 2002). However, the approach used previously, using a single BrdU injection and killing mice $2 \mathrm{~h}$ later, was aimed at labeling fast-dividing cells (i.e., type- $\mathrm{C}$ cells and neuroblasts). The protocol described here involved diluting BrdU in drinking water for $15 \mathrm{~d}$ followed by a relatively long-label free period, and exclusively stains (type-B) stem cells. In the present study, we confirm the identity of these candidate stem cells by double-staining for BrdU with GFAP or SOX2. We conclude that proliferation of candidate stem cells, but not fast dividing progenitors, is the main substrate for regulation by odor experience, in addition to the previous described effects on neuronal survival (Corotto et al., 1994; Petreanu and AlvarezBuylla, 2002; Rochefort et al., 2002; Miwa and Storm, 2005; Saghatelyan et al., 2005; Yamaguchi and Mori, 2005). This differential regulation of distinct cell pools suggests an interesting functional separation between slow- and fast-dividing cells in the SVZ.

Further work is required to explain how an enriched environment can modulate proliferation rates in candidate stem cells. Daily experience with new odorants produces an increase in sensory activity reaching the $\mathrm{OB}$, but is also accompanied by changes in the animal's internal state (i.e., changes in hormonal status or neurotransmitter systems, for instance). Whatever the mechanism, results from our study support the idea that the recruitment of newborn neurons into $\mathrm{OB}$ circuits closely correlates with the complexity of the olfactory environment.

We also demonstrate that transient lesion of the MOE stimulates the proliferation of candidate stem cells located in the adult RMS, but spares those in the SVZ. How can both MOE lesions and olfactory enrichment produce increases in RMS proliferation? Although MOE lesions reduce sensory afferents, they also involve cell death, immune responses, and regeneration processes. Previous reports have shown that olfactory nerve axotomy increases fast-dividing cell proliferation in the RMS and SVZ (Mandairon et al., 2003). Our results indicate distinct sensitivities of astrocytes to the lesion according to their respective location. Thus, in addition to constitutively providing the OB with newborn neurons, the RMS is also a reactive proliferative zone that responds to lesion, at least when it occurs in the olfactory epithelium. Hypothetically, factors produced by the degenerating epithelium may stimulate neural stem cell proliferation in the RMS (Battista et al., 2006). This potential mechanism would explain the gradient effect seen in Figure $7 D$, where the difference between treated and nontreated groups declined with increasing distance from the OB. Moreover, histological features in the most rostral part of the RMS, as possible remnants of the neonatal olfactory ventricle, could explain why only this region responds to an MOE lesion.

In the present study, it is difficult evaluate the effect of up- regulating RMS proliferation on the $\mathrm{OB}$ neuronal population. Although both MOE lesion and enrichment increase the number of $\mathrm{BrdU}^{+}$cells in the $\mathrm{OB}$ (data not shown), this result is difficult to interpret given that both treatments could also affect newborn neuron survival (Rochefort et al., 2002). Further experiments will be required to completely understand the impact on the OB network of stem cell proliferation increases in both the SVZ and RMS. Moreover, the increase in neural stem cell proliferation could also have local effects on neurogenic niche homeostasis. For instance, we cannot rule out the possibility that RMS proliferation might produce local astrocytes that could be considered as additional neural stem cells.

In summary, our demonstration that SVZ-derived versus RMS-derived stem cells can be differentially regulated, together with evidence that they are developmentally distinct populations (Kohwi et al., 2007; Young et al., 2007), offers new insights into the heterogeneity of adult neural stem cells in the SVZ-OB system, and help to define the permissive conditions that facilitate the production of newborn neurons in the adult forebrain.

\section{References}

Aguirre A, Gallo V (2004) Postnatal neurogenesis and gliogenesis in the olfactory bulb from NG2-expressing progenitors of the subventricular zone. J Neurosci 24:10530-10541.

Alvarez-Buylla A, Lim DA (2004) For the long run: maintaining germinal niches in the adult brain. Neuron 41:683-686.

Alvarez-Buylla A, García-Verdugo JM, Tramontin AD (2001) A unified hypothesis on the lineage of neural stem cells. Nat Rev Neurosci 2:287-293.

Batista-Brito R, Close J, Machold R, Fishell G (2008) The distinct temporal origins of olfactory bulb interneuron subtypes. J Neurosci 28:3966-3975.

Battista D, Ferrari CC, Gage FH, Pitossi FJ (2006) Neurogenic niche modulation by activated microglia: transforming growth factor beta increases neurogenesis in the adult dentate gyrus. Eur J Neurosci 23:83-93.

Bonfanti L, Peretto P (2007) Radial glial origin of the adult neural stem cells in the subventricular zone. Prog Neurobiol 83:24-36.

Brüstle O, Choudhary K, Karram K, Hüttner A, Murray K, Dubois-Dalcq M, McKay RD (1998) Chimeric brains generated by intraventricular transplantation of fetal human brain cells into embryonic rats. Nat Biotechnol 16:1040-1044.

Carleton A, Petreanu LT, Lansford R, Alvarez-Buylla A, Lledo PM (2003) Becoming a new neuron in the adult olfactory bulb. Nat Neurosci 6:507-518.

Corotto FS, Henegar JR, Maruniak JA (1994) Odor deprivation leads to reduced neurogenesis and reduced neuronal survival in the olfactory bulb of the adult mouse. Neuroscience 61:739-744.

Curtis MA, Faull RL, Eriksson PS (2007) The effect of neurodegenerative diseases on the subventricular zone. Nat Rev Neurosci 8:712-723.

Deloulme JC, Raponi E, Gentil BJ, Bertacchi N, Marks A, Labourdette G, Baudier J (2004) Nuclear expression of S100B in oligodendrocyte progenitor cells correlates with differentiation toward the oligodendroglial lineage and modulates oligodendrocytes maturation. Mol Cell Neurosci 27:453-465.

Doetsch F, García-Verdugo JM, Alvarez-Buylla A (1997) Cellular composition and three-dimensional organization of the subventricular germinal zone in the adult mammalian brain. J Neurosci 17:5046-5061.

Doetsch F, Caillé I, Lim DA, García-Verdugo JM, Alvarez-Buylla A (1999a) Subventricular zone astrocytes are neural stem cells in the adult mammalian brain. Cell 97:703-716.

Doetsch F, García-Verdugo JM, Alvarez-Buylla A (1999b) Regeneration of a germinal layer in the adult mammalian brain. Proc Natl Acad Sci U S A 96:11619-11624.

Espósito MS, Piatti VC, Laplagne DA, Morgenstern NA, Ferrari CC, Pitossi FJ, Schinder AF. (2005) Neuronal differentiation in the adult hippocampus recapitulates embryonic development. J Neurosci 25:10074-10086.

Ferri AL, Cavallaro M, Braida D, Di Cristofano A, Canta A, Vezzani A, Ottolenghi S, Pandolfi PP, Sala M, DeBiasi S, Nicolis SK (2004) Sox2 deficiency causes neurodegeneration and impaired neurogenesis in the adult mouse brain. Development 131:3805-3819. 
Gritti A, Bonfanti L, Doetsch F, Caille I, Alvarez-Buylla A, Lim DA, Galli R, Verdugo JM, Herrera DG, Vescovi AL (2002) Multipotent neural stem cells reside into the rostral extension and olfactory bulb of adult rodents. J Neurosci 22:437-445.

Grubb MS, Nissant A, Murray K, Lledo PM (2008) Functional maturation of the first synapse in olfaction: development and adult neurogenesis. J Neurosci 28:2919-2932.

Hack MA, Saghatelyan A, de Chevigny A, Pfeifer A, Ashery-Padan R, Lledo PM, Götz M (2005) Neuronal fate determinants of adult olfactory bulb neurogenesis. Nat Neurosci 8:865-872.

Jackson EL, Garcia-Verdugo JM, Gil-Perotin S, Roy M, Quinones-Hinojosa A, VandenBerg S, Alvarez-Buylla A (2006) PDGFR alpha-positive B cells are neural stem cells in the adult SVZ that form glioma-like growths in response to increased PDGF signaling. Neuron 51:187-199.

Jiao J, Chen DF (2008) Induction of neurogenesis in nonconventional neurogenic regions of the adult central nervous system by niche astrocyteproduced signals. Stem Cells 26:1221-1230.

Kohwi M, Petryniak MA, Long JE, Ekker M, Obata K, Yanagawa Y, Rubenstein JL, Alvarez-Buylla A (2007) A subpopulation of olfactory bulb GABAergic interneurons is derived from Emx1- and Dlx5/6-expressing progenitors. J Neurosci 27:6878-6891.

Lemasson M, Saghatelyan A, Olivo-Marin JC, Lledo PM (2005) Neonatal and adult neurogenesis provide two distinct populations of newborn neurons to the mouse olfactory bulb. J Neurosci 25:6816-6825.

Lledo PM, Alonso M, Grubb MS (2006) Adult neurogenesis and functional plasticity in neuronal circuits. Nat Rev Neurosci 7:179-193.

Lois C, Alvarez-Buylla A (1994) Long-distance neuronal migration in the adult mammalian brain. Science 264:1145-1148.

Luskin MB (1993) Restricted proliferation and migration of postnatally generated neurons derived from the forebrain subventricular zone. Neuron 11:173-189.

Magavi SS, Mitchell BD, Szentirmai O, Carter BS, Macklis JD (2005) Adultborn and preexisting olfactory granule neurons undergo distinct experience-dependent modifications of their olfactory responses in vivo. J Neurosci 25:10729-10739.

Mandairon N, Jourdan F, Didier A (2003) Deprivation of sensory inputs to the olfactory bulb up-regulates cell death and proliferation in the subventricular zone of adult mice. Neuroscience 119:507-516.

Menezes JR, Smith CM, Nelson KC, Luskin MB (1995) The division of neuronal progenitor cells during migration in the neonatal mammalian forebrain. Mol Cell Neurosci 6:496-508.

Merkle FT, Tramontin AD, García-Verdugo JM, Alvarez-Buylla A (2004) Radial glia give rise to adult neural stem cells in the subventricular zone. Proc Natl Acad Sci U S A 101:17528-17532.

Merkle FT, Mirzadeh Z, Alvarez-Buylla A (2007) Mosaic organization of neural stem cells in the adult brain. Science 317:381-384.

Miwa N, Storm DR (2005) Odorant-induced activation of extracellular signal-regulated kinase/mitogen-activated protein kinase in the olfactory bulb promotes survival of newly formed granule cells. J Neurosci 25:5404-5412.

Panagiotakos G, Alshamy G, Chan B, Abrams R, Greenberg E, Saxena A, Bradbury M, Edgar M, Gutin P, Tabar V (2007) Long-term impact of radiation on the stem cell and oligodendrocyte precursors in the brain. PLoS ONE 2:e588.

Peretto P, Giachino C, Aimar P, Fasolo A, Bonfanti L (2005) Chain formation and glial tube assembly in the shift from neonatal to adult subventricular zone of the rodent forebrain. J Comp Neurol 487:407-427.
Petreanu L, Alvarez-Buylla A (2002) Maturation and death of adult-born olfactory bulb granule neurons: role of olfaction. J Neurosci 22:6106-6113.

Polito A, Reynolds R (2005) NG2-expressing cells as oligodendrocyte progenitors in the normal and demyelinated adult central nervous system. J Anat 207:707-716.

Raponi E, Agenes F, Delphin C, Assard N, Baudier J, Legraverend C, Deloulme JC (2007) S100B expression defines a state in which GFAPexpressing cells lose their neural stem cell potential and acquire a more mature developmental stage. Glia 55:165-177.

Rochefort C, Gheusi G, Vincent JD, Lledo PM (2002) Enriched odor exposure increases the number of newborn neurons in the adult olfactory bulb and improves odor memory. J Neurosci 22:2679-2689.

Rousselot P, Lois C, Alvarez-Buylla A (1995) Embryonic (PSA) N-CAM reveals chains of migrating neuroblasts between the lateral ventricle and the olfactory bulb of adult mice. J Comp Neurol 351:51-61.

Saghatelyan A, Roux P, Migliore M, Rochefort C, Desmaisons D, Charneau P, Shepherd GM, Lledo PM (2005) Activity-dependent adjustments of the inhibitory network in the olfactory bulb following early postnatal deprivation. Neuron 46:103-116.

Sakaguchi M, Shingo T, Shimazaki T, Okano HJ, Shiwa M, Ishibashi S, Oguro H, Ninomiya M, Kadoya T, Horie H, Shibuya A, Mizusawa H, Poirier F, Nakauchi H, Sawamoto K, Okano H (2006) A carbohydrate-binding protein, Galectin-1, promotes proliferation of adult neural stem cells. Proc Natl Acad Sci U S A 103:7112-7117.

Shen Q, Goderie SK, Jin L, Karanth N, Sun Y, Abramova N, Vincent P, Pumiglia K, Temple S (2004) Endothelial cells stimulate self-renewal and expand neurogenesis of neural stem cells. Science 304:1338-1340.

Sirven A, Pflumio F, Zennou V, Titeux M, Vainchenker W, Coulombel L, Dubart-Kupperschmitt A, Charneau P (2000) The human immunodeficiency virus type- 1 central DNA flap is a crucial determinant for lentiviral vector nuclear import and gene transduction of human hematopoietic stem cells. Blood 96:4103-4110.

Suhonen JO, Peterson DA, Ray J, Gage FH (1996) Differentiation of adult hippocampus-derived progenitors into olfactory neurons in vivo. Nature 383:624-627.

Vedin V, Slotnick B, Berghard A (2004) Zonal ablation of the olfactory sensory neuroepithelium of the mouse: effects on odorant detection. Eur J Neurosci 20:1858-1864.

Watson DJ, Kobinger GP, Passini MA, Wilson JM, Wolfe JH (2002) Targeted transduction patterns in the mouse brain by lentivirus vectors pseudotyped with VSV, Ebola, Mokola, LCMV, or MuLV envelope proteins. Mol Ther 5:528-537.

Yamaguchi M, Mori K (2005) Critical period for sensory experiencedependent survival of newly generated granule cells in the adult mouse olfactory bulb. Proc Natl Acad Sci U S A 102:9697-9702.

Yoon H, Enquist LW, Dulac C (2005) Olfactory inputs to hypothalamic neurons controlling reproduction and fertility. Cell 123:669-682.

Young KM, Fogarty M, Kessaris N, Richardson WD (2007) Subventricular zone stem cells are heterogeneous with respect to their embryonic origins and neurogenic fates in the adult olfactory bulb. J Neurosci 27:8286-8296.

Zennou V, Petit C, Guetard D, Nerhbass U, Montagnier L, Charneau P (2000) HIV-1 genome nuclear import is mediated by a central DNA flap. Cell 101:173-185. 